\title{
Aseguramiento de la calidad en formación técnica de nivel superior y la incidencia de los planes de mejoramiento institucional ${ }^{*}$
}

DOI: https://doi.org/10.18046/recs.i34.4229

\author{
Norma Cárdenas-Saldaña ${ }^{* *}$ \\ Universidad de los Lagos (Osorno, Chile)
}

\section{Francisco Ganga-Contreras ${ }^{* * *}$}

Universidad de Tarapacá (Arica, Chile)

Cristian Aguilar-Ruiz ${ }^{* * * *}$

Universidad de los Lagos (Osorno, Chile)

\footnotetext{
* Este artículo es resultado del trabajo en la línea de investigación en Formación Técnica que el Departamento de Educación de la Universidad de Los Lagos (Chile) declara como parte de su plan estratégico departamental. La investigación fue financiada por la Política de incentivo a publicaciones del Departamento de Educación de la Universidad de Los Lagos (Chile). Artículo de investigación recibido el 15.08.2020 y aceptado el 11.03.2021.

** Doctora en Educación y Sociedad, Universidad Autónoma de Barcelona (España). Académica del Departamento de Educación de la Universidad de Los Lagos (Chile).Correo electrónico:norma.cardenas@ulagos.cl ORCID: https://orcid. org/oooo-ooo3-2244-1731

*** Doctor en Gestión Estratégica y Negocios Internacionales, Universidad de Sevilla (España). Posdoctorado en Ciencias Humanas, Universidad del Zulia (Venezuela). Consultor internacional y profesor titular del Departamento de Educación de la Facultad de Educación y Humanidades de la Universidad de Tarapacá (Chile). Página web personal: https://www. franciscoganga.cl/ Correo electrónico: franciscoganga@academicos.uta.cl ORCID: https://orcid.org/oooo-ooo19325-6459

**** Sociólogo, Universidad de La Frontera (Chile). Magíster en Ciencias Sociales, Universidad de Los Lagos (Chile). Analista Políticas Educativas, Departamento de Educación, Universidad de Los Lagos (Chile). Correo electrónico: cristian.aguilar@ulagos.cl ORCID: https://orcid.org/oooo-ooo3-3930-2092
} 


\section{Cómo citar/How to cite}

Cárdenas-Saldaña, Norma; Ganga-Contreras, Francisco; Aguilar-Ruiz, Cristian (2021).

Aseguramiento de la calidad en formación técnica de nivel superior y la incidencia de los planes de mejoramiento institucional. Revista CS, 34, 127-165. https://doi.org/10.18046/recs.i34.4229 


\section{Resumen}

El objetivo de la investigación presentada en este artículo es analizar el impacto de planes de mejoramiento institucional (PMI) en resultados de acreditación para institutos técnicos de nivel superior en Chile, entendiendo que asegurar la calidad es crucial para ofrecer servicios educacionales de excelencia, siendo la acreditación su indicador de logro. Mediante metodología cualitativa, se revisaron resultados de acreditación institucional, analizando fortalezas y debilidades para las áreas evaluadas. Los resultados muestran que, si bien existe una relación relativa entre implementación de PMI y años de acreditación obtenidos, los datos recogidos son insuficientes para demostrar su impacto; esto se debe a que no se encontraron relaciones entre las áreas evaluadas y las mejoras propuestas por PMI. En conclusión, se recomienda una revisión exhaustiva de asignación de recursos, así como de las condiciones en las que se implementan debiendo identificarse su impacto en la mejora de la calidad en Chile.

\section{PALABRAS CLAVE:}

formación profesional, formación técnica de nivel superior, aseguramiento de calidad, planes de mejoramiento institucional, acreditación

The objective of this research is to analyze the impact of Institutional Improvement Plans (PMI) on accreditation results for the Higher-level Technical Institutes, in Chile, understanding that ensuring quality is crucial to providing educational services of excellence, being accreditation its achievements indicator. Through a qualitative methodology, the results of institutional accreditation were reviewed, by analyzing strengths and weaknesses for the areas assessed. The results show that while is there a relative relationship between the implementation of PMI and the accreditation-years obtained, the data collected are insufficient to demonstrate its impact, since the relationships between the areas evaluated and the improvements proposed by the PMI were not found. In conclusion, it is recommended to perform a comprehensive review of the allocation of resources and conditions under which it is applied, as well as the identification of its true impact on quality improvement, in Chile.

\section{KEYWORDS:}

Professional Training, Technical Institutes, Quality Assurance, Quality Improvement Plans, Accreditation 



\section{Introducción}

El presente trabajo explora la incidencia de los planes de mejoramiento institucional (PMI) en el aseguramiento de la calidad (AC) de las instituciones que imparten formación técnica de nivel superior (FTNS), ratificada en la acreditación institucional obtenida luego de su implementación. El AC se entiende como el "conjunto de políticas, procedimientos, normas y prácticas (internas y externas a las instituciones y sus programas) destinados a la mantención y promoción de estándares de calidad (Zapata; Tejeda, 2009: 193). Desde esa perspectiva, el AC es una prioridad de las instituciones. En consonancia con ello, estas apelan a modelos de gestión eficientes, instalan prácticas y esperan resultados notables para la gestión de la docencia y, en el caso de la formación técnica de nivel superior, la efectiva vinculación con el medio socioproductivo y la garantía de la empleabilidad como elementos centrales, para lo cual deben movilizarse recursos suficientes que permitan desplegar acciones y constatar evidencias (Donoso; Corvalán, 2012; Romero; Montt; Arancibia, 2020).

Uno de los dispositivos que ha permitido financiar acciones en torno al AC son los PMI: propiciaron la instalación de procesos formativos en carreras técnicas alineadas con modelos basados en competencias, mediante fuertes inversiones en iniciativas que consoliden prácticas para implementar modelos institucionales que cumplan con los requerimientos de la ley 20190 de aseguramiento de calidad y que, por tanto, garanticen una mejoría en la calidad de la formación comprometida en los propósitos institucionales, además de generar dinámicas capaces de mejorar las condiciones de oferta de capital humano especializado, de acuerdo con los requerimientos del medio socio-productivo (Donoso; Corvalán, 2012).

Con esa finalidad se estableció el compromiso de lograr mejoramientos académicos y de gestión, con resultados en indicadores de gran impacto; se creó, por lo tanto, una relación directa respecto del modo en que dichos indicadores constituyen una evidencia medible del aseguramiento de la calidad, que la Comisión Nacional de Acreditación (CNA) evalúa por áreas. En el período 2015 se adjudicaron 8 PMI vinculados a la oferta de FTNS (Mineduc, 2015), cuyos montos de financiamiento oscilaron entre $\mathrm{M} \$ 300$ y $\mathrm{M} \$ 700$. Dado que existe evidencia para constatar esta conexión entre el despliegue de los PMI en las instituciones adjudicadas y su contribución al desarrollo de mejores niveles de calidad en las diferentes áreas evaluadas por la CNA -tales como Gestión institucional (GI), Docencia de pregrado (DP) y Vinculación con el medio (VcM)-, se analizará cómo han impactado estos planes de mejora en los resultados de acreditación, los que forman parte del modelo concursable de asignación de recursos del estado para la educación, al que las instituciones de educación superior postulan, adjudican e implementan. 


\section{Fundamentos teóricos}

\section{Antecedentes contextuales de la FTNS}

En el sistema de educación superior chileno, la FTNS es impartida en centros de formación técnica (CFT), institutos profesionales (IP) y universidades indistintamente, los cuales son regulados por las normas de aseguramiento de calidad que emanan de la Comisión Nacional de Acreditación (CNA); estos permiten comparar el desarrollo y la consolidación de sus proyectos institucionales.

La FTNS fue definida por la Unesco (2015a) como aquella área educativa que se ocupa de impartir conocimientos y capacidades para el mundo del trabajo. En esta línea, la Ley de Educación Superior Chilena 21.091 ha establecido de manera específica que tanto los IP como los CFT son instituciones cuya misión formar profesionales y técnicos capaces de contribuir al desarrollo de los distintos sectores productivos y sociales del país, que deberán promover la articulación con todos los niveles y tipos de formación técnico-profesional, y vincularse con el mundo del trabajo.

Este nivel formativo tiene una larga tradición en Chile: de acuerdo con los registros del Ministerio de Educación (Mineduc), hay iniciativas que datan de 1798, como la Academia San Luis y el Consejo de la Educación Técnica. Entre 1930 y 1947 se crearon la Universidad Técnica Federico Santa María - UTFS y la Universidad Técnica del Estado - UTE (Biblioteca Nacional de Chile, 2021). En la década de 1960 surgieron otras instituciones que ampliaron y diversificaron la oferta de formación técnica de índole privada, como Inacap y Duoc, vigentes hasta hoy. Años más tarde, en 1981, con la implementación de la reforma conocida como "Privatización de la Educación", se crearon los IP y los CFT, de tal manera que se consolidó la presencia de gestores privados que comenzarían a recibir recursos del estado como mecanismo de financiamiento para mejorar sus proyectos institucionales. $Y$ en épocas más recientes, en el 2016, se promulgó la Ley 20.910 en el marco de una "Nueva Educación Pública", que posibilita la creación de una oferta Estatal de educación técnica de nivel superior en todas las regiones del país; mandata la instalación de 15 CFT, vinculados a una Universidad Pública presente en el territorio.

En el caso de los IP, se los autoriza a impartir carreras profesionales sin licenciatura además de las técnicas de nivel superior; los CFT, por su parte, se concentran exclusivamente en esta última oferta. El cuadro 1 muestra la información de 100 instituciones de educación superior, públicas y privadas, que en la actualidad se ocupan de este nivel formativo. La FTNS es de ciclo corto; esto es, su duración oscila entre 2 y 3 años (Mineduc, 2021a). 


\begin{tabular}{|c|c|c|c|}
\hline CUADRO 1 & Distribución de instituciones que imparten carreras de FTNS & \\
\hline Tipo de institución & Públicos & Privados & Total \\
\hline Centros de formación técnica & 8 & 38 & $\mathbf{4 6}$ \\
\hline Institutos profesionales & 0 & 28 & $\mathbf{2 8}$ \\
\hline Universidades & 11 & $\mathbf{2 6}$ & $\mathbf{2 6}$ \\
\hline Total & $\mathbf{1 9}$ & $\mathbf{8 1}$ & $\mathbf{1 0 0}$ \\
\hline
\end{tabular}

Resulta interesante reconocer que, en Chile, la FTNS ha sostenido un incremento de la matrícula; representa la titulación preferida de quienes se matricularon en primer año el 2017 (Consejo Nacional de Educación - CNED, 2017). Esto resulta interesante dado que la oferta de Educación Superior en Chile se ha centrado en carreras de ciclos largos que los postulantes relacionaban, aparentemente, con un mayor prestigio social y una mejor remuneración (Duarte; Saldoval, 2017). Así entonces, vemos que la matrícula muestra un incremento entre los años 2012 a 2019 de 304.419 a 344.231 estudiantes, respectivamente (CNED, 2020), lo que representa un aumento de $11,6 \%$ (cuadro 2).

CUADRO 2 $\mid$ Matrículas en carreras FTNS, por año y tipo de institución (2012-2019)

\begin{tabular}{|c|c|c|c|c|c|c|c|c|}
\hline $\begin{array}{c}\text { Tipo de } \\
\text { instituciones }\end{array}$ & 2012 & 2013 & 2014 & 2015 & 2016 & 2017 & 2018 & 2019 \\
\hline $\begin{array}{l}\text { Centros de } \\
\text { formación técnica }\end{array}$ & 140.031 & 144.365 & 148.010 & 146.540 & 141.711 & 136.777 & 136.730 & 137.940 \\
\hline $\begin{array}{l}\text { Institutos } \\
\text { profesionales }\end{array}$ & 135.185 & 150.837 & 169.741 & 186.153 & 191.561 & 186.689 & 183.144 & 179.754 \\
\hline Universidades & 29.203 & 32.271 & 31.114 & 29.183 & 28.442 & 29.795 & 29.422 & 26.537 \\
\hline Total general & 304.419 & 327.473 & 348.865 & 361.876 & 361.714 & 353.261 & 349.296 & 344.231 \\
\hline
\end{tabular}


Respecto de la titulación, el periodo 2012-2016 arroja un 59,5\% más de titulados en FTNS, a diferencia del 23,2 \% de las carreras profesionales con licenciatura (Mineduc, 2017). Esto reduce la brecha en la proporción de técnicos versus profesionales, señalado por la Sociedad de Fomento Fabril (Sofofa) como preocupante para sostener el desarrollo del país (El Mercurio On-Line - EMOL, 2017).

Dado el espacio que hoy ocupa la FTNS, la política pública fomenta su desarrollo con recursos garantizados por las leyes de presupuesto y sus glosas. Los PMI, a disposición de estas instituciones, definieron propósitos orientados a fortalecen sus procesos formativos y garantizan la calidad de otros indicadores, asociados a una mayor retención de los estudiantes y una mejor inserción laboral, acorde a los requerimientos del medio socioproductivo.

\section{Formación técnica y el sistema de aseguramiento de la calidad de la educación superior chilena}

El AC de la educación superior en el sistema educativo chileno inicia su formalización en el año 2006 con la promulgación de la Ley de Aseguramiento de la Calidad de la Educación Superior (Ley 20.129), mediante la cual se instala un Sistema de Aseguramiento de la Calidad (SAC) que opera a través de la integración de varias unidades como el Mineduc y la CNA, entre otras.

El sistema desarrolla políticas de aseguramiento de la calidad para la Educación Superior mediante la acreditación de instituciones y programas formativos, en el marco de una certificación pública de la calidad. De forma específica, con la acreditación se busca

fomentar y dar garantía pública de la calidad de las Instituciones de Educación Superior (IES) autónomas, de sus programas de pregrado y de postgrado, verificar la sustentabilidad económica a fin de asegurar la estabilidad y viabilidad institucional a través de ejercicios sistemáticos de evaluación. (Lemaite; Maturana; Zenteno; Alvarado, 2012; Goeffroy, 2014)

Las áreas de acreditación de la CNA para las IES, en las que se incluyen los CFT, son cinco, y se dividen en obligatorias y optativas: las primeras corresponden a la gestión institucional y la docencia de pregrado; y las segundas a la vinculación con el medio, la docencia de posgrado y la investigación. Las instituciones presentan un informe de autoevaluación, fruto del análisis interno de sus fortalezas y debilidades. Este es constatado por una visita de pares externos, quienes emiten otro informe de evaluación "desarrollado sobre la base de los antecedentes entregados por la institución, aquellos obtenidos en la visita u otros que sean utilizados para corro- 
borar, verificar o complementar la información contenida en los antecedentes de la institución", según el artículo 16 del Reglamento que fija el procedimiento para el desarrollo de los procesos de acreditación institucional de la CNA. En síntesis, el informe de autoevaluación, junto con otro de carácter financiero (CNA, Artículo 7, Reglamento para procedimiento de acreditación institucional) (CNA, 2019) y el informe externo, son la base central de la decisión de acreditación que toma la CNA.

$\mathrm{El}$ artículo 19 del reglamento indica que "se otorgará la acreditación institucional a las instituciones de educación superior que cumplan con los criterios de evaluación", y que la CNA puede pronunciarse en torno a 607 años en el caso de la acreditación de excelencia; entre 4 y 5 en la acreditación avanzada; y en un tiempo de 3 años en la básica. Por su parte, el artículo 22 expresa que la institución podrá interponer un recurso de reposición respecto de la decisión de acreditación y solo en caso de no ser acreditadas, las instituciones podrán apelar ante el Consejo Nacional de Educación dentro del plazo de 30 (treinta) días hábiles, contados desde la fecha en que se notifica la resolución que se impugna, de conformidad a lo dispuesto en el artículo $23 .^{\circ}$ de la Ley 20.129.

$\mathrm{Si}$ bien es cierto que el reglamento por medio del cual se fija el procedimiento de acreditación institucional fue actualizado el año 2019, ninguno de los artículos mencionados difiere del contenido del reglamento que fija el procedimiento para el desarrollo de los procesos de acreditación institucional, contenido en la resolución exenta CNA DJ n. ${ }^{\circ}$ oo9-4 del 13 de octubre de 2014. Con estos lineamientos, un gran número de IES en el ámbito de la formación técnica se ha acreditado en las áreas obligatorias y, en algunos casos, en la optativa de Vinculación con el medio. El cuadro 3 sintetiza la información sobre las áreas, criterios y elementos esperados.

La FTNS debe garantizar propósitos y fines institucionales claros, políticas y mecanismos formales y eficientes en concordancia con herramientas de aseguramiento de la calidad, constatados en resultados clave tales como la adecuada inserción laboral. En el cuadro 3 se aprecia que, principalmente, se insiste en la correcta planificación y gestión institucional, en el ajuste de la oferta de las carreras o la modificación de perfiles de egreso, dentro de lo que se incorporan los adelantos de los procesos productivos y laborales, y se consideran las necesidades del mercado laboral, entre otros aspectos.

La progresión de los estudiantes, los indicadores de empleabilidad y seguimiento de titulados resultan clave, y dan cuenta de un proceso que demuestra prácticas sistemáticas de AC. Por otra parte, se espera que las actividades de Vinculación con el medio guarden una estrecha relación bidireccional y sean sistematizadas y monitoreadas en su impacto, sobre todo a nivel de los procesos formativos. 
CUADRO 3 Áreas, criterios y elementos esperados en el proceso de acreditación de la FTNS

\begin{tabular}{|c|c|c|}
\hline Áreas & Criterios & Lo esperado \\
\hline \multirow{3}{*}{$\begin{array}{l}\text { Gestión institucional } \\
\text { - GI (obligatoria) }\end{array}$} & $\begin{array}{l}\text { Planificación y desarrollo } \\
\text { del proyecto institucional }\end{array}$ & \multirow{3}{*}{$\begin{array}{l}\text { La institución debe contar con un pro- } \\
\text { yecto educativo fundamentado en una } \\
\text { misión que se evalúa periódicamente y } \\
\text { está en concordancia con las condicio- } \\
\text { nes de operación que se ponen a dispo- } \\
\text { sición, tanto para el cumplimiento del } \\
\text { proceso formativo como en lo que atañe } \\
\text { a servicios de apoyo eficaz a los estu- } \\
\text { diantes. }\end{array}$} \\
\hline & Administración y recursos & \\
\hline & $\begin{array}{l}\text { Servicios orientados a los } \\
\text { estudiantes }\end{array}$ & \\
\hline \multirow[b]{3}{*}{$\begin{array}{l}\text { Docencia de pregrado - } \\
\text { DP (obligatoria) }\end{array}$} & Carreras & \multirow{3}{*}{$\begin{array}{l}\text { La institución promueve una oferta for- } \\
\text { mativa que responde a las necesidades e } \\
\text { innovación del medio socioproductivo, } \\
\text { en la que se consideran resultados como } \\
\text { progresión, inserción laboral y segui- } \\
\text { miento de los titulados, y se hace énfasis } \\
\text { en procesos y estrategias metodológicas } \\
\text { que incluyan la experiencia profesional } \\
\text { y laboral de los docentes. }\end{array}$} \\
\hline & Docentes & \\
\hline & Resultados & \\
\hline \multirow[b]{2}{*}{$\begin{array}{l}\text { Vinculación con el } \\
\text { medio - VcM (optativa) }\end{array}$} & $\begin{array}{l}\text { Diseño y provisión de } \\
\text { actividades }\end{array}$ & \multirow{2}{*}{$\begin{array}{l}\text { La institución da cuenta de una articu- } \\
\text { lación bidireccional con el entorno sig- } \\
\text { nificante que se plasma en su misión, } \\
\text { actividades y procesos formativos vin- } \\
\text { culados a los requerimientos del medio } \\
\text { socioproductivo, dentro de lo cual se } \\
\text { evalúa de manera sistemática el impac- } \\
\text { to para el entorno como la propia insti- } \\
\text { tución. }\end{array}$} \\
\hline & Resultados e impacto & \\
\hline
\end{tabular}

$\mathrm{El} 5 \mathrm{O} \%$ de las 100 instituciones catastradas en la base de datos de matrículas de SIES Mineduc entre los años 2017-2019, y que imparten carreras FTNS están acreditadas con un promedio de 2 años, bajo el sistema de Aseguramiento de la Calidad.

Tal como lo revela el cuadro 4, no todas las instituciones que imparten FTNS se encuentran acreditadas. Esto se relaciona con lo dictaminado por el artículo 15 del título II de la Ley 20.129 de Aseguramiento de la Calidad de la Educación Superior (2006): "Las universidades, institutos profesionales y centros de formación técnica autónomos podrán someterse a procesos de acreditación institucional ante la CNA (...) La opción por el proceso de acreditación será voluntaria” (Mineduc; Ley 20.219 de 2006). 

\begin{tabular}{l|l} 
CUADRO 4 & $\begin{array}{l}\text { Distribución de instituciones que imparten carreras técnicas de nivel } \\
\text { superior en Chile y estado de acreditación voluntaria }\end{array}$
\end{tabular}

\begin{tabular}{|c|c|c|c|c|c|}
\hline \multirow[t]{2}{*}{ Tipo de institución } & \multicolumn{2}{|c|}{ |Acreditados } & \multicolumn{2}{|c|}{ No acreditados } & Total \\
\hline & $\mathbf{n}$ & $\%$ & $\mathbf{n}$ & $\%$ & \\
\hline Centros de formación técnica & 15 & $32,60 \%$ & 31 & $67,40 \%$ & \\
\hline Públicos & 3 & $6,50 \%$ & 5 & $10,90 \%$ & 46 \\
\hline Privados & 12 & $26,10 \%$ & 26 & $56,50 \%$ & \\
\hline Institutos profesionales & 13 & $46,40 \%$ & 15 & $53,60 \%$ & \\
\hline Públicos & o & o,oo \% & o & $0,00 \%$ & 28 \\
\hline Privados & 13 & $46,40 \%$ & 15 & $53,60 \%$ & \\
\hline Universidades & 22 & $84,60 \%$ & 4 & $15,40 \%$ & \\
\hline Públicos & 11 & $42,30 \%$ & $\mathrm{o}$ & $0,00 \%$ & 26 \\
\hline Privados & 11 & $42,30 \%$ & 4 & $15,40 \%$ & \\
\hline
\end{tabular}

La Ley 21.091 de Educación Superior, promulgada en 2018, introdujo algunos cambios, y de modo específico en lo que refiere a la voluntariedad del proceso de acreditación; así entonces, se modificó el Artículo 15 en el siguiente sentido: "Reemplázase su inciso primero por el siguiente: 'Artículo 15.- La acreditación institucional será obligatoria para las instituciones de Educación Superior autónomas"” (Mineduc; Ley 20.219 de 2006).

Como consecuencia de lo anterior, los procesos de acreditación vigentes fueron realizados en la mayoría de las instituciones antes de la promulgación de la Ley en 2018, en el marco de dicha voluntariedad. Distinto es el caso de las universidades que imparten formación técnica: si bien operaron en el marco de la Ley 20.129, diversas normativas, referidas a estar acreditadas como condición para obtener financiamiento estatal ${ }^{1}$ o recursos con garantía fiscal destinados al financiamiento de los estudios de los alumnos, terminaron por instalar la obligatoriedad en ellas.

La ley contempla, además, la existencia de un subsistema técnico profesional integrado por CFT Estatales, IP y CFT privados reconocidos por el Estado; e igual-

1. Tal es el caso del Crédito con Aval del Estado para financiamiento de los estudiantes o, posteriormente, la gratuidad universitaria, que partió de manera gradual primero para Universidades y carreras profesionales, y hoy es un beneficio desplegado también para FTNS. 
mente hace hincapié en que las diferentes ofertas que coexisten en el sistema de Educación Superior deben dar garantías de un marco mínimo de orientación. En el caso de la formación técnica se espera el desarrollo de capacidades referidas a un pensamiento autónomo y crítico, basado en el conocimiento de disciplinas vinculadas al mundo del trabajo (CNA, 2013). Del mismo modo, la ley dice que el Mineduc debe definir una "Estrategia Nacional de Formación Técnico Profesional" que aporte a la generación y aplicación de políticas públicas que fortalezcan el área; de igual manera, destaca la creación de trayectorias formativas laborales en sintonía con las necesidades personales y de los sectores productivos, que aporten a los resultados de la titulación y a una mayor inserción laboral, cuestiones que no escapan a la mirada de organismos internacionales (Ley 20.219 de 2006, título 2, artículo 16).

Desde iniciativas como la organización de seminarios, la Unesco (2015) ha ratificado la preeminencia del sector (París, 1987-1989; Seúl, 1999; Shanghái, 2012, etc.). Otros documentos orientadores vigentes, tales como la "Agenda de Educación 2030" y la "Estrategia para la Enseñanza y Formación Técnica y Profesional (EFTP) 20162021", dan fe de ello. Hoy se impulsan ideas cuyo foco está puesto en "que los jóvenes que optan por este camino adquieran las competencias y habilidades necesarias para su desarrollo y puedan, por esta vía, contribuir al progreso del país" (EFTP, 2O2O:4).

\section{Aseguramiento de la calidad en formación técnica desde la perspectiva comparada internacional}

El sistema educativo chileno ha orientado sus esfuerzos a la exploración de sistemas educativos de otras latitudes con más tradición y que ostenten resultados exitosos en cuanto a calidad del proceso formativo e inserción laboral, en busca de factores capaces de aportar a la calidad y con la pretensión de identificar fórmulas que permitan transferirlos a la realidad nacional (Wiedenslaufer; Cifuentes; Holz, 2015).

Respecto de lo anterior, justamente Canadá, Alemania y Australia son países que pudiesen ser considerados buenos referentes en el sentido planteado; por ello, el análisis se centra en "la articulación de esta modalidad con otras formas educativas e instituciones de educación superior (articulación vertical y horizontal) y su vinculación con el medio productivo" (Weidenslaufer et al., 2015:2).

La participación del medio socioproductivo en Canadá, Alemania y Australia es respaldada con la intervención de representantes de la industria en organismos de regulación y diseño de contenidos y certificaciones en este nivel educativo y de sistemas nacionales de instrucción en la empresa (Weidenslaufer et al., 2015), lo que determina una vinculación formal, sistemática y ligada a temas de decisiones curriculares y de financiamiento. Asimismo, la formación dual (FD) en Alemania y 
Australia, por ejemplo, constituye un elemento digno de tomar en cuenta a la hora de reconocer la vinculación efectiva con la empresa en países con sistemas de formación técnica más consolidados. En Chile, dicha experiencia se ha extendido mucho más en el ámbito de la formación media técnico-profesional; puede que sorprenda el que no se haya aplicado a nivel superior y que aún no existan incentivos para implementarla. Al respecto, se señala que la operación de este sistema dual "depende de la existencia de ciertas condiciones previas que no emergen automáticamente a lo largo de diferentes contextos institucionales e históricos" (Sevilla, 2017: 17).

Algunas investigaciones de otros países (Bauer; Gessler, 2016; Pineda-Herrero; Arnau-Sabatés; Ciraso-Calí, 2019) muestran que el nivel competencial y madurativo del alumnado de nivel superior facilita el desarrollo de la formación dual y aumenta la eficacia de la formación profesional en su conjunto. Otro instrumento notable, presente en estas naciones, apunta a un "Marco Nacional de Cualificaciones" (Mineduc, 2020) basado en competencias. Pese a que hay distinciones entre las propuestas, el eje central es la definición y estructura de competencias laborales articuladas en los diferentes niveles del sistema y con la empresa.

En Chile se cuenta con un marco regulatorio en este sentido, denominado "Marco de Cualificaciones Técnico Profesional" (Mineduc, 2020), que busca aportar a una ruta formativa laboral exitosa a partir del reconocimiento de las competencias laborales claves que el sector productivo demanda. En la actualidad se implementa un plan piloto de cualificaciones, cuyos resultados significarán un avance para la FTNS en el ajuste de los currículos y metodologías de enseñanza-aprendizaje.

Otro de los elementos que claramente se identifican como claves en países con más efectividad en sus resultados de formación técnica es la vinculación formal con la empresa y los mecanismos de articulación formativa. Se espera, además, que esta vinculación inste a la innovación, el emprendimiento y la competitividad "puesto que la visión de la ESTP se plantea como una que se encuentre directamente enhebrada en la estrategia de desarrollo económico del país y su entorno próximo" (CNA, 2020: 31); para ello, quienes dirigen las instituciones formadoras deberían escuchar cuidadosamente las necesidades y requerimientos de los sectores interesados relevantes (Lašáková; Bajzíková; Dedze, 2017).

Para el caso del sistema educativo chileno, en las leyes 21.091 de educación superior y 21.910, así como en la Estrategia Nacional para la Formación Técnico Profesional de Chile (Mineduc, 2020), se indica la importancia de esa vinculación y articulación con la empresa. En el caso de los CFT estatales regulados por la ley 21.910, se indica claramente que estos deben "entregar formación pertinente a través de una vinculación efectiva con el sector productivo de su región, orientada hacia el desempeño en el mundo laboral" (Ley 21.910, artículo $4 .^{\circ}$, letra c). Esta perspectiva 
va en la línea "del enfoque técnico-funcionalista que mira a la educación técnica como una formación especializada en función de los requerimientos del aparato productivo" (Sevilla, 2014: 313).

Sin embargo, esta funcionalidad implica, a su vez, comprometer a la empresa para que sea consultora permanente en materias curriculares, labor para la cual esta deberá destinar parte de su tiempo. Si bien se indica la importancia de esta vinculación entre institución y empresa, no se clarifica cómo se ha garantizar que funcione esta articulación entre instituciones cuyos objetivos, formas de resolver y modelos de gestión son muy diversos. Por tanto, la participación de la empresa no tiene un modelo único: puede definirse según los sectores económicos, estructurarse por regiones o resolverse a nivel de cada institución (Sevilla, 2017: 19).

En el caso de la articulación efectiva, según datos del Mineduc en 2008, un 21 $\%$ de estudiantes egresados de EMTP ingresaba de inmediato a la Educación Superior, cifra que ascendió a $44 \%$ en 2017. Con este panorama y como una forma de promover proceso de articulación más sistémicos se formalizó en enero de 2020 el Primer Acuerdo Nacional de Convalidación y Articulación, como mecanismo efectivo de articulación entre la EMTP y la ESTP. Esto resulta relevante, sobre todo cuando datos de la Comisión Nacional para la Productividad (2018) muestran que la educación técnico-superior ofrece una rentabilidad del orden de $25 \%$; por lo tanto, "se considera que el país está maduro para garantizar la educación técnica superior (CFT o equivalente) a todo joven que egrese de la enseñanza media" (Comisión Nacional de Productividad, 2018: 25).

\section{Dispositivos con financiamiento estatal para la mejora de la calidad de la formación técnica}

Uno de los dispositivos con financiamiento estatal enfocado a mejorar los resultados en las instituciones educativas son los PMI, instalados a modo de contratos entre el Estado y las instituciones. En el caso de la FT, en 2015 se destinaron recursos específicos para desarrollar estos convenios operacionalizados mediante los PMI. Estos fondos de financiamiento concursables se orientaron a apoyar el desarrollo de procesos de innovación e introducir mejoras en distintos ámbitos del quehacer, tales como infraestructura, actualización del equipamiento e implementación de diseños curriculares que incorporaran la formación basada en competencias, aun cuando en este nivel formativo sus primeros antecedentes se reconocieron hacia el año 200o, en Miranda (2003) y Hinrichsen y Villela (2003).

La formación basada en competencias debería venir a solucionar la preocupación de garantizar que los técnicos se encuentren preparados a la hora de enfrentar 
los desafíos del mundo laboral, por consiguiente, el desarrollo de los saberes y las competencias de los futuros técnicos está estrechamente ligado con mejorar las oportunidades laborales en aras de facilitar la incorporación al mundo del trabajo. (Sistema de Información de Tendencias Educativas en América Latina - Siteal, 2019). Por tanto, la vinculación de la empresa es una de las bases del proceso formativo: agiliza la conexión y el desarrollo de las competencias laborales. Por esto, resultan fundamentales los modelos curriculares basados en competencias en los que se han identificado las necesidades de formación y la definición de los perfiles de egreso en conjunto con el medio socio-productivo, son fundamentales (Donoso; Corvalán, 2012). Por ende, apostar por PMI en FTNS ${ }^{2}$ supone la contribución al mejoramiento de indicadores y a la vinculación con la empresa, reflejada en mecanismos de aseguramiento de la calidad. Al promulgar estas iniciativas, el Mineduc manifestó que los PMI a los que postulaban las instituciones apoyarían el desarrollo de procesos formativos en carreras técnicas actualizadas e innovadoras, alineadas con las necesidades del mercado laboral, que llevaran a una mayor provisión de formación técnica de alta calidad. El apoyo de recursos dedicado a la mejora de la formación técnico-profesional fue de 1.500.00o USD para un periodo de tres años, prorrogables por un solo otros 12 meses.

Mediante este PMI, y considerando un diagnóstico estratégico, las instituciones se comprometían a lograr mejoramientos académicos y de gestiones notables, medidos en indicadores de gran contundencia e impacto. Igualmente, debían referirse a los resultados de la acreditación institucional y de programas, e incluir una síntesis de las resoluciones de la CNA; esto es, se establecía una relación directa en cuánto o cómo estos indicadores, resultado de la focalización del recurso público, resultaban una evidencia medible del aseguramiento de la calidad.

Una de las principales fortalezas de la implementación de estos planes resulta del seguimiento y monitoreo continuo sobre la base de control permanente, como lo subrayan Reich, Machuca, López, Prieto, Music, Rodríguez-Ponce y Yutronic (2011: 14). No obstante, es importante que los planes de mejoramiento logren anclarse en el nivel estratégico institucional y focalizarse en instituciones con condiciones de asumir tales desafíos.

2. De acuerdo con información del Manual Operacional del Programa de Financiamiento por Resultados de la Educación Terciaria - "MECESUP3, 2014. 


\section{Metodología}

La investigación presentada aquí es de índole cualitativa y base documental; por tanto, se recurrió a un enfoque metodológico que incluye el estudio de casos comparados (Yin, 2004; Flick, 2004). Este se sustentó en un análisis diagnóstico descriptivo de las condiciones estructurales del sistema educacional para la FTNS, además de un análisis de contenido sobre dictámenes de acreditación a los que han sido sometidas las instituciones ejecutoras de PMI. Se esperó extraer interpretaciones generales acorde a los procesos de acreditación que han sucedido antes y después de que las instituciones adhirieron al PMI 2015.

Las instituciones consideradas como muestra en el estudio (cuadro 5) fueron analizadas a partir del mecanismo de financiamiento PMI, el cual es de carácter estatal

CUADRO 5 Instituciones con PMI 2015 según códigos de plan y de análisis

\begin{tabular}{|c|c|c|c|c|}
\hline $\begin{array}{c}\text { Tipo de } \\
\text { institución }\end{array}$ & $\begin{array}{l}\text { Código } \\
\text { del plan }\end{array}$ & $\begin{array}{c}\text { Código de } \\
\text { análisis de la }\end{array}$ & \multicolumn{2}{|c|}{ Dictámenes analizados } \\
\hline & & & Pre & Post \\
\hline \multirow{4}{*}{$\begin{array}{l}\text { Centro de formación } \\
\text { técnica (CFT) }\end{array}$} & EGR15O1 & CFT_EGR15O1 & $\begin{array}{c}2014 \\
\text { AC }\end{array}$ & $\begin{array}{c}2016 \\
\mathrm{AC}^{*} \mathrm{RE}^{*} \mathrm{AP}^{*}\end{array}$ \\
\hline & CEN15O1 & CFT_CEN15O1 & $\begin{array}{c}2012 \\
\mathrm{AC}\end{array}$ & $\begin{array}{l}2016 \\
\mathrm{AC}\end{array}$ \\
\hline & CIC15O1 & $\mathrm{CFT}_{-} \mathrm{CIC}_{15 \mathrm{O}}$ & $\begin{array}{c}2012 \\
\mathrm{AC}\end{array}$ & $\begin{array}{c}2016-2019 \\
\text { AC RE AP - AC RE }\end{array}$ \\
\hline & CPA15O1 & CFT_CPA15O1 & $\begin{array}{c}2012 \\
\mathrm{AC}\end{array}$ & $\begin{array}{c}2014-2018 \\
\text { AC RE - AC RE }\end{array}$ \\
\hline $\begin{array}{l}\text { Instituto profesional } \\
\text { (IP) }\end{array}$ & IAR15O1 & IP_IAR15O1 & $\begin{array}{c}2012 \\
\mathrm{AC}\end{array}$ & $\begin{array}{c}2016 \\
\mathrm{AC} R E\end{array}$ \\
\hline \multirow{2}{*}{ Universidad (U) } & ULA1501 & U_ULA1501 & $\begin{array}{c}2013 \\
\mathrm{AC}\end{array}$ & $\begin{array}{c}2016 \\
\mathrm{AC} R E\end{array}$ \\
\hline & MAG1501 & U_MAG15O1 & $\mathrm{AC}$ & $\begin{array}{c}2015-2019 \\
A C-A C\end{array}$ \\
\hline
\end{tabular}

${ }^{*} \mathrm{AC}$ : Acuerdo de acreditación

${ }^{* *}$ RE: Acuerdo de recurso de reposición ante la Comisión Nacional de Acreditación

${ }^{* *}$ AP: Acuerdo con Apelación ante Consejo Nacional de Educación 
y constituye información pública oficial. De las ocho que en 2015 se adjudicaron un plan de mejoramiento, se seleccionaron siete que cumplen con la característica de ser instituciones formadoras del ámbito civil y se dejó fuera una, perteneciente a las Fuerzas Armadas.

Se recurrió a bases de datos oficiales del Mineduc con vistas a contar con un alcance descriptivo del comportamiento de la matrícula, la titulación y la oferta académica de las instituciones seleccionadas. Se revisaron los dictámenes de acreditación institucional elaborados por la CNA, con base en aspectos normalizados tanto en la Ley 20.129 de AC como en los procedimientos oficiales. Se analizaron diez dictámenes correspondientes al periodo anterior a la adjudicación del PMI, y dieciséis de hasta dos periodos de acreditación posteriores. La información se interpretó de acuerdo con las categorías presentadas en el cuadro 6, para lo cual se realizó un análisis de contenido instrumentalizado y de medición de frecuencias de enunciado por cada categoría analítica. Esto reveló fortalezas y debilidades, dilucidadas conforme a las relaciones entre PMI y acreditación institucional.

\begin{tabular}{l|l} 
CUADRO 6 & $\begin{array}{l}\text { Áreas, categorías y subcategorías de análisis para el proceso } \\
\text { de acreditación de la FTNS }\end{array}$
\end{tabular}

\begin{tabular}{|c|c|c|c|}
\hline $\begin{array}{c}\text { Áreas de } \\
\text { acreditación }\end{array}$ & $\begin{array}{l}\text { Categorías de } \\
\text { análisis }\end{array}$ & $\begin{array}{l}\text { Subcategorías } \\
\text { de análisis }\end{array}$ & $\begin{array}{l}\text { Dimensiones } \\
\text { de análisis }\end{array}$ \\
\hline \multirow{10}{*}{$\begin{array}{l}\text { Gestión } \\
\text { institucional - GI } \\
\text { (obligatoria) }\end{array}$} & \multirow{4}{*}{$\begin{array}{c}\text { Planificación } \\
\text { y desarrollo del } \\
\text { proyecto } \\
\text { institucional }\end{array}$} & 1.A Misión y propósitos & \multirow{10}{*}{$\begin{array}{l}\text { Cada subcategoría } \\
\text { considerará el } \\
\text { dictamen del criterio } \\
\text { según las dimensiones } \\
\text { en las que se expresa: } \\
\text { fortaleza/debilidad }\end{array}$} \\
\hline & & $\begin{array}{l}\text { 2.A Estructura } \\
\text { organizacional }\end{array}$ & \\
\hline & & $\begin{array}{l}\text { 3.A Capacidad de } \\
\text { autorregulación }\end{array}$ & \\
\hline & & 4.A Gobierno institucional & \\
\hline & \multirow{4}{*}{$\begin{array}{l}\text { Administración } \\
\text { y recursos }\end{array}$} & 5.A Gestión de personas & \\
\hline & & $\begin{array}{l}\text { 6.A Información } \\
\text { institucional }\end{array}$ & \\
\hline & & 7.A Recursos materiales & \\
\hline & & $\begin{array}{l}\text { 8.A Sustentabilidad } \\
\text { económico-financiera }\end{array}$ & \\
\hline & \multirow{2}{*}{$\begin{array}{l}\text { Servicios orientados } \\
\text { a los estudiantes }\end{array}$} & 9.A Servicios de apoyo & \\
\hline & & 10.A Difusión y publicidad & \\
\hline
\end{tabular}




\begin{tabular}{|c|c|c|}
\hline \multirow{8}{*}{$\begin{array}{l}\text { Docencia de } \\
\text { pregrado - DP } \\
\text { (obligatorio) }\end{array}$} & \multirow{3}{*}{ Carreras } & $\begin{array}{l}\text { 1.B Diseño y provisión de } \\
\text { carreras }\end{array}$ \\
\hline & & $\begin{array}{l}\text { 2.B Proceso de enseñanza- } \\
\text { aprendizaje }\end{array}$ \\
\hline & & $\begin{array}{l}\text { 3.B Innovación de } \\
\text { contenidos }\end{array}$ \\
\hline & \multirow{2}{*}{ Docentes } & 4.B Dotación \\
\hline & & 5.B Calificación \\
\hline & \multirow{3}{*}{ Resultados } & 6.B Progresión \\
\hline & & 7.B Inserción laboral \\
\hline & & $\begin{array}{l}\text { 8.B Seguimiento de } \\
\text { egresados }\end{array}$ \\
\hline \multirow{4}{*}{$\begin{array}{l}\text { Vinculación con } \\
\text { el medio - VcM } \\
\text { (optativo) }\end{array}$} & \multirow{2}{*}{$\begin{array}{l}\text { Diseño y provisión } \\
\text { de actividades }\end{array}$} & 1.C Coherencia \\
\hline & & $\begin{array}{l}\text { 2.C Condiciones de } \\
\text { operación }\end{array}$ \\
\hline & \multirow{2}{*}{ Resultados e impacto } & 3.C Resultados \\
\hline & & 4.C Impacto \\
\hline
\end{tabular}

Fuente: elaboración propia a partir de criterios CNA para evaluación institucional FT.

Respecto de las limitaciones de esta investigación, se constata la escasez de información sobre el nivel formativo FTNS en cuanto al aseguramiento de la calidad como política pública en relación con las herramientas de índole financiera que para ello se han dispuesto - los PMI son una de ellas-. Escasamente se ha indagado en torno a su impacto en las instituciones, en las estructuras organizacionales y de gestión; dado que el tema no ha sido abordado con suficiencia, se requiere avanzar en esta materia en una perspectiva más longitudinal y de estudio de casos, que este escrito no considera. 


\section{Resultados}

\section{Descripción de PMI para instituciones financiadas y sus áreas de acreditación asociadas a los planes adjudicados}

Las instituciones beneficiadas con PMI 2015 presentan una fuerte inversión (sobre los 490 millones de pesos chilenos (637.00o USD aproximadamente ${ }^{3}$ ), destinada al fortalecimiento de sus áreas de acreditación. Vale destacar las diferentes políticas institucionales sostenidas en aras de fortalecer la institución, asegurar la calidad y lograr una correspondencia entre el quehacer institucional y sus propósitos (cuadro 7).

\begin{tabular}{|c|c|c|c|c|c|c|}
\hline CUADRO 7 & \multicolumn{6}{|c|}{$\begin{array}{l}\text { Planes adjudicados como PMI 2015, montos y áreas comprometidas } \\
\text { para desarrollo de objetivos }\end{array}$} \\
\hline \multirow[t]{2}{*}{ Institución } & Título de PMI & $\begin{array}{l}\text { Monto de } \\
\text { inversión }\end{array}$ & $\begin{array}{l}\mathbf{N}^{\circ} \\
\text { Sedes }\end{array}$ & \multicolumn{3}{|c|}{ Objetivos } \\
\hline & & & & GI & DP & VcM \\
\hline CFT_EGR15O1 & $\begin{array}{l}\text { Enlázate Quinta Región: Fortaleci- } \\
\text { miento y consolidación del modelo } \\
\text { por competencias laborales de CFT } \\
\text { UV para una articulación efectiva con } \\
\text { el sector productivo, liceos EMTP y la } \\
\text { universidad. }\end{array}$ & 577.560 & 1 & - & $\sqrt{ }$ & $\sqrt{ }$ \\
\hline CFT_CEN15O1 & $\begin{array}{l}\text { Currículo basado en competencias } \\
\text { laborales: innovación curricular, pro- } \\
\text { ceso formativo de calidad y vincula- } \\
\text { ción con el sector productivo. }\end{array}$ & 697.811 & 1 & $\sqrt{ }$ & $\sqrt{ }$ & $\sqrt{ }$ \\
\hline CFT_CIC15O1 & $\begin{array}{l}\text { Renovación y rediseño de los servi- } \\
\text { cios formativos, para una mejor in- } \\
\text { serción laboral de nuestros alumnos } \\
\text { actuales y futuros, desarrollando las } \\
\text { confianzas y compromisos con las } \\
\text { empresas regionales para ser un alia- } \\
\text { do estratégico clave. }\end{array}$ & 699.500 & 1 & $\sqrt{ }$ & $\sqrt{ }$ & $\sqrt{ }$ \\
\hline CFT_CPA15O1 & $\begin{array}{l}\text { Consolidación y fortalecimiento del } \\
\text { modelo educativo basado en com- } \\
\text { petencias del CFT ProAndes y de su } \\
\text { vinculación con la industria. }\end{array}$ & 699.700 & 5 & $\sqrt{ }$ & $\sqrt{ }$ & $\sqrt{ }$ \\
\hline
\end{tabular}

3. Según el tipo de cambio del 28 de julio del 2020. 


\begin{tabular}{|c|c|c|c|c|c|c|}
\hline IP_IAR15O1 & $\begin{array}{l}\text { Rediseño curricular enfocado en } \\
\text { competencias, apoyado por plan de } \\
\text { perfeccionamiento docente, recur- } \\
\text { sos de apoyo y gestión integrada para } \\
\text { mejorar la calidad de la oferta forma- } \\
\text { tiva técnica y profesional. }\end{array}$ & 493.340 & 14 & - & $\sqrt{ }$ & $\sqrt{ }$ \\
\hline U_ULA1501 & $\begin{array}{l}\text { Consolidando la Formación Técnica } \\
\text { en la Universidad Estatal de la Re- } \\
\text { gión de Los Lagos: propuesta para } \\
\text { mejorar el acceso, la articulación, la } \\
\text { pertinencia con el medio sociopro- } \\
\text { ductivo regional y el aseguramiento } \\
\text { de la calidad. }\end{array}$ & 700.000 & 4 & $\sqrt{ }$ & $\sqrt{ }$ & $\sqrt{ }$ \\
\hline ; & $\begin{array}{l}\text { Convenio de desempeño para forma- } \\
\text { ción técnico-profesional en la Uni- } \\
\text { versidad de Magallanes: fortalecer la } \\
\text { enseñanza técnico-profesional de la } \\
\text { universidad a través de la reestructu- } \\
\text { ración de la organización administra- } \\
\text { tiva y el rediseño curricular de toda } \\
\text { la oferta académica en cada una de } \\
\text { sus sedes universitarias, a través de } \\
\text { mecanismos de aseguramiento de la } \\
\text { calidad que permitan su autoevalua- } \\
\text { ción y mejora permanente, en con } \\
\text { concordancia con las líneas propues- } \\
\text { tas por el Ministerio de Educación, y } \\
\text { considerando el modelo que se está } \\
\text { utilizando para el diseño del CFT } \\
\text { Público que se propone implementar } \\
\text { para la Región de Magallanes }\end{array}$ & 628.218 & 2 & $\sqrt{ }$ & $\sqrt{ }$ & $\sqrt{ }$ \\
\hline
\end{tabular}

Fuente: elaboración propia.

Las condiciones en las que se imparte el proceso formativo deben considerar una gestión institucional que contribuya a la generación de políticas que desarrollen condiciones de operación sobre las demás dinámicas transversales e incluyan una amplia vinculación con el medio, que impacte también en la docencia de pregrado. También se espera que los proyectos educativos consoliden una gestión institucional que facilite la toma de decisiones, con miras al desarrollo de las áreas que la CNA evalúa, tarea que a veces se transforma en algo difícil de lograr, dada las escasas competencias organizacionales que tienen algunos equipos directivos.

La dispersión geográfica, es decir, el número de sedes donde se distribuye la oferta académica, constituye un rasgo fundamental de los proyectos educativos y los sitúa en un escenario complejo, pues implica garantizar la homogeneidad de la 
oferta de forma tal que se pueda conocer la progresión de las carreras y homologar los resultados del proceso formativo de forma equivalente en todas las sedes. Muestra de ello es el IP_IAR1501, que cuenta con 14 sedes en el territorio nacional.

De las instituciones analizadas, seis se encuentran acreditadas después de la adjudicación del PMI 2015 (cuadro 8); una de ellas, el Instituto Profesional IP_IAR1501, cerró sus operaciones porque no consiguió mejorar su calidad pese a las labores de fortalecimiento, lo que devela una incongruencia entre los compromisos adquiridos y las condiciones de operación. ElCFT_CEN15O1, que propone mejoras en su modelo educacional y un cambio hacia un modelo de formación por competencias, sobresale porque alcanza buenos resultados y obtiene seis años de acreditación, lo que habla de una institución que logra asegurar calidad de su oferta formativa sistemáticamente.

Las universidades que imparten FT muestran resultados de acreditación favorables desde los 4 años. Ello evidencia la instalación de prácticas de calidad sistemática, con procesos y políticas que consolidan ciertas fortalezas que promueven la calidad de los servicios educacionales.

En el cuadro 9 se especifican las diferencias de las instituciones en cuanto a su experiencia en procesos de autoevaluación y acreditación, lo que no siempre constituye una ventaja en sí. Por ejemplo, el CFT_CIC15O1, a pesar de haberse acreditado

\begin{tabular}{l|l} 
CUADRO 8 & $\begin{array}{l}\text { Caracterización de acreditación vigente, instituciones de educación } \\
\text { superior que imparten FTNS con PMI 2015 adjudicado }\end{array}$
\end{tabular}

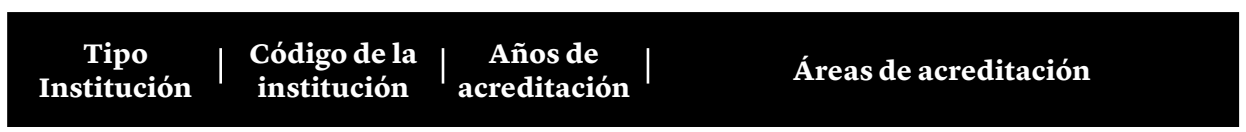

\begin{tabular}{|c|c|c|c|c|c|}
\hline & & & $\begin{array}{c}\text { Gestión ins- } \\
\text { titucional }\end{array}$ & $\begin{array}{c}\text { Docencia de } \\
\text { pregrado }\end{array}$ & $\begin{array}{l}\text { Vincula- } \\
\text { ción con el } \\
\text { medio }\end{array}$ \\
\hline \multirow{4}{*}{$\begin{array}{l}\text { Centro de } \\
\text { formación } \\
\text { técnica }\end{array}$} & CFT_EGR15O1 & 3 & $\sqrt{ }$ & $\sqrt{ }$ & - \\
\hline & CFT_CEN15O1 & 6 & $\sqrt{ }$ & $\sqrt{ }$ & - \\
\hline & CFT_CIC15O1 & 2 & $\checkmark$ & $\checkmark$ & - \\
\hline & CFT_CPA15O1 & 2 & $\sqrt{ }$ & $\sqrt{ }$ & - \\
\hline $\begin{array}{l}\text { Instituto } \\
\text { profesional }\end{array}$ & IP_IAR1501 & o & - & - & - \\
\hline \multirow{2}{*}{ Universidad } & U_ULA1501 & 4 & $\sqrt{ }$ & $\sqrt{ }$ & $\checkmark$ \\
\hline & U_MAG15O1 & 4 & $\sqrt{ }$ & $\sqrt{ }$ & $\sqrt{ }$ \\
\hline
\end{tabular}


en dos procesos anteriores - y contando con financiamiento y compromiso de PMI-, en el último debió recurrir, luego de una apelación a la CNA, a un recurso de reposición en el Consejo Nacional de Educación (CNED). A nivel institucional, lo anterior se percibe como un problema grave en la consolidación de la misión y propósitos institucionales, que impacta transversalmente en las áreas de autoevaluación.

En el caso de CFT_CEN_15O1 es interesante el manejo del aprendizaje institucional y la promoción de buenas prácticas para la mejora continua; se lo cataloga como institución de excelencia (cualificación que se obtiene con entre 6 y 7 años de acreditación institucional, según la CNA). De acuerdo con el criterio de la entidad evaluadora, ello supone contar con políticas internas y sistemas organizacionales capaces de sostener el aseguramiento de la calidad y capacidad de autorregulación interna, lo que lleva a sustentar la oferta formativa.

CUADRO 9 Experiencia de acreditación en instituciones educación superior que imparten carreras técnicas de nivel superior beneficiadas con PMI 2015

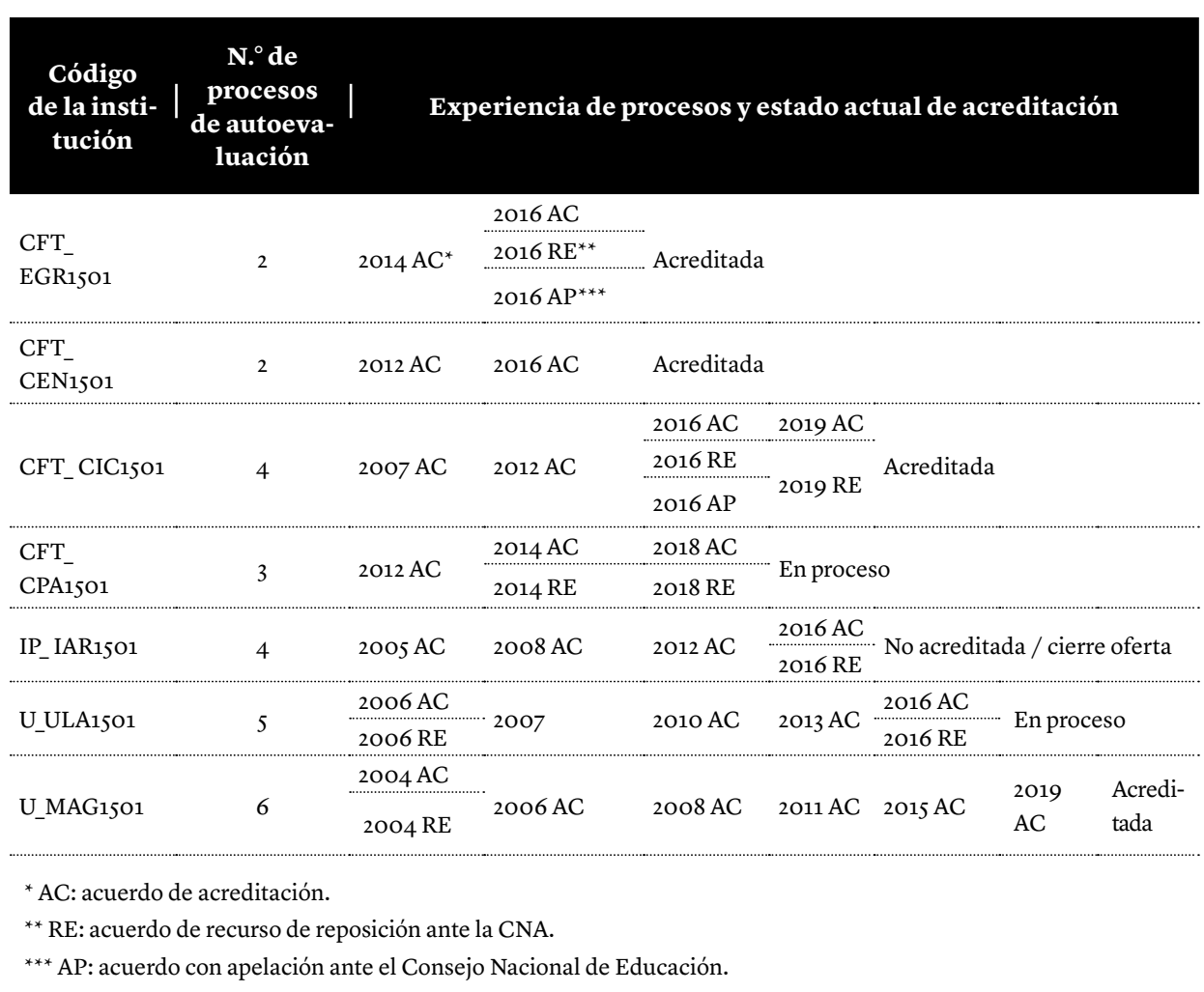


Aun cuando la oferta de programas de FTNS disminuyó solo alrededor de un 7 $\%$, la matrícula descendió en un $40 \%$, fundamentalmente desde el año 2017. Lo anterior sucedió en todos los planteles a excepción de dos: CEN 15O1, donde la cifra de estudiantes aumentó de modo significativo; $\mathrm{IAR} 1501$, donde la oferta formativa y de operaciones continuaba decreciendo hasta el cierre de esta pesquisa (cuadro 10).

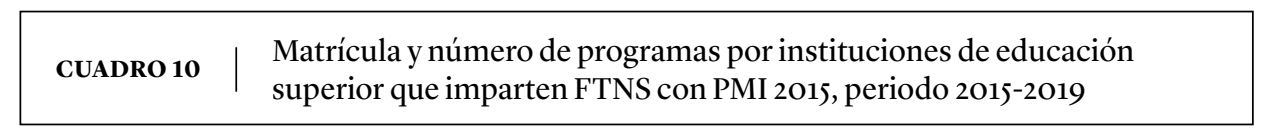

\begin{tabular}{|c|c|c|c|c|c|c|c|c|c|c|}
\hline \multirow{2}{*}{ Institución } & \multicolumn{5}{|c|}{ Matrícula } & \multicolumn{5}{|c|}{ N. ${ }^{\circ}$ de programas } \\
\hline & 2015 & 2016 & 2017 & 2018 & 2019 & 2015 & 2016 & 2017 & 2018 & 2019 \\
\hline CFT_EGR15O1 & 872 & 938 & 892 & 822 & 826 & 14 & 15 & 16 & 17 & 15 \\
\hline CFT_CEN15O1 & 3258 & 3765 & 4573 & 5735 & 7351 & 19 & 22 & 25 & 26 & 30 \\
\hline CFT_CIC15O1 & 812 & 885 & 804 & 899 & 713 & 11 & 15 & 11 & 14 & 11 \\
\hline CFT_CPA15O1 & 3445 & 3829 & 3815 & 2856 & 2319 & 21 & 23 & 27 & 20 & 19 \\
\hline IP_IAR15O1 & 12533 & 11294 & 6458 & 1800 & 88 & 39 & 39 & 40 & 37 & 17 \\
\hline U_ULA1501 & 3451 & 3381 & 3510 & 3558 & 3240 & 14 & 16 & 15 & 16 & 14 \\
\hline U_MAG15O1 & 1169 & 1136 & 1018 & 987 & 826 & 20 & 17 & 17 & 25 & 23 \\
\hline Total general & 25540 & 25228 & 21070 & 16657 & 15363 & 138 & 147 & 151 & 155 & 129 \\
\hline
\end{tabular}

El cuadro 11 expone los resultados de la titulación, la retención y la empleabilidad en la etapa 2015-2019; se pone de manifiesto que la titulación representa una fracción cercana al $25 \%$, constante entre el número de matriculados para la cohorte de ingreso. Una paulatina instalación de mecanismos para el seguimiento de la progresión académica ha permitido avanzar en los índices de retención y titulación mediante un seguimiento de competencias en el perfil de egreso, prácticas e inserción laboral de manera dinámica. Esto tiende a mejorar gradualmente ciertas condiciones del proceso formativo relacionadas con procesos de titulación, que hoy constituyen evidencias solicitadas por la CNA con el objetivo de asegurar que las carreras poseen estos criterios desde su diseño y provisión. En los últimos procesos de acreditación, el criterio Vinculación con el Medio (VcM) comienza a ser operacional y no declarativo, como lo fue en un primer momento, lo que crea una amplia presión del sector socioproductivo por participar en los consejos asesores de las instituciones de FTNS, junto con la demanda permanente de profesionales especializados. 
Promedios de retención y empleabilidad en el primer año por

CUADRO 11 instituciones de educación superior que imparten FTNS con PMI 2015, periodo $2015-2018$

\begin{tabular}{|c|c|c|c|c|c|c|c|c|c|}
\hline $\begin{array}{l}\text { Institu- } \\
\text { ción }\end{array}$ & $\begin{array}{l}\text { TIT } \\
2012\end{array}$ & $\begin{array}{l}\text { TIT_ } \\
2013\end{array}$ & $\begin{array}{l}\text { TIT_ } \\
2014\end{array}$ & $\begin{array}{l}\text { TIT_ } \\
2015\end{array}$ & $\begin{array}{l}\text { TIT_ } \\
2016\end{array}$ & $\begin{array}{l}\text { TIT } \\
2017\end{array}$ & $\begin{array}{l}\text { TIT } \\
2018\end{array}$ & $\begin{array}{c}\text { Promedio } \\
\text { de retención, } \\
\text { 1.er año }\end{array}$ & $\begin{array}{l}\text { Promedio de } \\
\text { empleabili- } \\
\text { dad, 1.er año }\end{array}$ \\
\hline $\begin{array}{l}\mathrm{CFT}_{-} \\
\text {EGR15O1 }\end{array}$ & 75 & 89 & 95 & 243 & 273 & 165 & 184 & $67,59 \%$ & $48,31 \%$ \\
\hline $\begin{array}{l}\mathrm{CFT}_{-} \\
\mathrm{CEN1501}\end{array}$ & 684 & 739 & 702 & 828 & 739 & 736 & 807 & $77,70 \%$ & $57,98 \%$ \\
\hline $\begin{array}{l}\mathrm{CFT}_{-} \\
\mathrm{CIC}_{15 \mathrm{O} 1}\end{array}$ & 153 & 134 & 179 & 167 & 186 & 217 & 274 & $68,09 \%$ & $28,70 \%$ \\
\hline $\begin{array}{l}\mathrm{CFT}_{-} \\
\text {CPA15O1 }\end{array}$ & 194 & 261 & 469 & 561 & 577 & 799 & 826 & $60,95 \%$ & $45,47 \%$ \\
\hline IP_IAR15O1 & 1341 & 1553 & 2011 & 2311 & 2753 & 2774 & 2245 & $\mathrm{~s} / \mathrm{i}$ & $61,65 \%$ \\
\hline U_ULA1501 & 235 & 215 & 310 & 500 & 845 & 788 & 898 & $78,64 \%$ & $66,09 \%$ \\
\hline $\begin{array}{l}\mathrm{U}_{-} \\
\mathrm{MAG} 1501\end{array}$ & 77 & 101 & 173 & 195 & 165 & 222 & 177 & $69,99 \%$ & $47,76 \%$ \\
\hline $\begin{array}{l}\text { Total } \\
\text { general }\end{array}$ & 2759 & 3092 & 3939 & 4805 & 5538 & 5701 & 5411 & & \\
\hline
\end{tabular}

Descripción de resultados por áreas de autoevaluación, fortalezas y debilidades presentes en el grupo instituciones previos a la adjudicación de PMI 2015 [T2]

Los dictámenes de acreditación brindan la posibilidad de conocer, de modo referencial, los criterios sobre las fortalezas y debilidades que arroja la implementación de los planes institucionales de las casas de estudio analizadas. En principio, los discernimientos entre una institución y otra tienden a ser disímiles, de manera que se tomaron como base los criterios de autoevaluación de la CNA para instituciones que imparten FTNS, segmento que comprende CFT, IP y universidades.

Se llevó a cabo un análisis de contenido con la finalidad de comprender, desde el momento de la codificación, las diferentes situaciones institucionales observadas por expertos, contrastadas con actores internos y externos, estudiantes, empleadores, miembros de comités asesores y docentes, entre otros. Esto compone los resultados de la evaluación que, finalmente, otorga una determinada cantidad de años de acreditación, todo plasmado en un dictamen legal. 
Las instituciones beneficiarias del PMI 2015 surgieron desde una experiencia institucional en vías de consolidación, en momentos previos a la adjudicación del PMI y su financiamiento; sustentaban su modelo educativo y los proyectos académicos asentadas de forma esencial en las fortalezas de su gestión institucional. Según los datos recogidos en el cuadro 12, los CFT y las universidades comparten promedios de fortalezas en su misión y propósitos institucionales, en la capacidad de autorregulación, los recursos materiales y la sustentabilidad del proyecto académico que en conjunto promueven las condiciones hacia la docencia de pregrado y la vinculación con el medio.

En el caso del IP, la evaluación inicial contiene una serie de ambigüedades respecto de la instalación de mecanismos que promuevan las buenas prácticas institucionales, hecho que limita la capacidad de reacción de la institución frente a las debilidades detectadas; estas son más bien de fondo en todas las áreas. Los diferentes sistemas organizacionales adoptados dejan ver que los mecanismos para GI y DP están principalmente fortalecidos como misiones y propósitos declarativos estructurados que propenden a un diseño y provisión de carreras pertinentes, lo que determina instituciones en procesos de estructuración encaminados a superar las brechas detectadas en las acreditaciones.

Las condiciones relacionadas con VcM antes de la adjudicación del PMI 2015 consideran solo declaraciones y no hay operacionalización de políticas institucionales que impacten el modelo formativo y la provisión de carreras, incluso con el posicionamiento de las instituciones a nivel local; solo se destaca un avance significativo en la creación de instancias para el reconocimiento de aprendizajes previos (RAP), y consejos asesores externos que permitirán fortalecer los aspectos operacionales desde la apertura de carreras hasta el posicionamiento de titulados a través de mecanismos de inserción laboral.

Las debilidades anteriores a la adjudicación de PMI 2015 apuntaban de forma sustancial a la GI, sus sistemas de seguimiento, la capacidad de autorregulación, la progresión académica, el seguimiento de egresados y la vinculación con el medio (cuadro 12). Las debilidades encontradas se relacionan con que no se consideran actores relevantes del medio socioproductivo en la apertura de nuevas carreras y tampoco se da respuesta a las demandas locales por especialización de capital humano. Otras condiciones de operación, como acceso a instalaciones adecuadas, capacidad de talleres y biblioteca actualizada, entre otros servicios para estudiantes, eran precarios en ese momento, o en muchos casos inexistentes. 
CUADRO 12

Frecuencia de enunciados para áreas de acreditación y criterios de acreditación para instituciones, previa adjudicación de PMI 2015

\begin{tabular}{|c|c|c|c|c|c|c|}
\hline \multirow{2}{*}{$\begin{array}{l}\text { Dimensiones de análisis } \\
\text { Áreas de autoevaluación }\end{array}$} & \multicolumn{3}{|c|}{ Fortalezas } & \multicolumn{3}{|c|}{ Debilidades } \\
\hline & $\begin{array}{l}\text { PROM } \\
\text { CFT }\end{array}$ & $\begin{array}{l}\text { PROM_ } \\
\text { IP }\end{array}$ & $\begin{array}{l}\text { PROM_ } \\
\text { UES }\end{array}$ & $\begin{array}{l}\text { PROM } \\
\text { CFT }\end{array}$ & $\begin{array}{c}\text { PROM } \\
\text { IP }\end{array}$ & $\begin{array}{c}\text { PROM } \\
\text { UES }\end{array}$ \\
\hline Gestión institucional & 13 & 6 & 16 & 13 & 6 & 10 \\
\hline 1.A Misión y propósitos & 3 & 1 & 5 & 2 & 3 & 1 \\
\hline 2.A Estructura organizacional & 1 & - & 2 & 1 & 1 & - \\
\hline $\begin{array}{l}\text { 3.A Capacidad de } \\
\text { autorregulación }\end{array}$ & 2 & - & 4 & 3 & - & 4 \\
\hline 4.A Gobierno institucional & 2 & 1 & 1 & 1 & 1 & 1 \\
\hline 5.A Gestión de personas & 1 & 1 & 1 & 1 & - & - \\
\hline 6.A Información institucional & 1 & 1 & 1 & 1 & 1 & - \\
\hline 7.A Recursos materiales & 2 & 1 & 1 & 2 & - & 2 \\
\hline $\begin{array}{l}\text { 8.A Sustentabilidad } \\
\text { económico-financiera }\end{array}$ & 1 & 1 & 2 & 2 & - & 1 \\
\hline 9.A Servicios de apoyo & 1 & - & - & - & - & - \\
\hline 10.A Difusión y publicidad & 1 & - & - & 1 & - & - \\
\hline Docencia pregrado & 13 & 3 & 6 & 7 & 3 & 8 \\
\hline $\begin{array}{l}\text { 1.B Diseño y provisión de } \\
\text { carreras }\end{array}$ & 2 & 1 & 3 & 1 & 1 & 3 \\
\hline $\begin{array}{l}\text { 2.B Proceso de enseñanza- } \\
\text { aprendizaje }\end{array}$ & 5 & - & 1 & 2 & - & 3 \\
\hline 3.B Innovación de Contenidos & 1 & - & - & - & - & - \\
\hline 4.B Dotación & 2 & 1 & 1 & 1 & 1 & 1 \\
\hline 5.B Calificación & 1 & 1 & 1 & - & 1 & 1 \\
\hline 6.B Progresión & 1 & - & - & 2 & - & - \\
\hline 7.B Inserción Laboral & - & - & - & 1 & - & - \\
\hline 8.B Seguimiento de Egresados & - & - & - & 1 & - & - \\
\hline
\end{tabular}




\begin{tabular}{|c|c|c|c|c|c|c|}
\hline Vinculación con el medio & 4 & - & 2 & $\mathbf{1}$ & - & $\mathbf{1}$ \\
\hline 1.C Coherencia & 2 & - & 1 & - & - & 1 \\
\hline 2.C Condiciones de operación & 1 & - & - & - & - & - \\
\hline 3.C Resultados & - & - & - & 1 & - & - \\
\hline 4.C Impacto & 1 & - & - & - & - & - \\
\hline
\end{tabular}

\section{CUADRO 13 Fortalezas y debilidades de las instituciones analizadas}

\section{Fortalezas}

Área GI. Criterio de capacidad de autorregulación:

U_ULA_2013: "La universidad cuenta con un modelo educativo en el que se definen propósitos y objetivos, principios y valores que guían los procesos de aprendizaje. Contiene 5 principios: compromiso con la calidad, con el pluralismo, con la ética y la transparencia; con la participación y la democracia y; con la diversidad cultural y la interculturalidad. Se distingue el enfoque curricular, el enfoque pedagógico y evaluación del aprendizaje".

Área GI. Criterio de recursos materiales:

CFT_CPA_2014: “El centro evalúa el uso eficaz y la actualización de los recursos físicos e intelectuales, y aplica un proceso anual que permite identificar requerimientos y planificar la datación de recursos físicos y materiales".

Área DP. Criterio de área de diseño y provisión de carreras:

CFT_CIC_2012: “El centro ha realizado avances que le han permitido fortalecer sus mecanismos de aseguramiento de calidad en las distintas áreas institucionales. En este sentido, destaca la definición de objetivos estratégicos, la incorporación de cuerpos colegiados y autoridades unipersonales en su organización, la creación de la Dirección de Gestión Institucional orientada al seguimiento de procesos y resguardo de la calidad, la definición de directrices para el perfil de los docentes, el desarrollo de una formulación presupuestaria con

\section{Debilidades}

Área GI. Criterio de misión y propósito institucional:

CFT_CEN_2012: "Aun cuando la institución ha decidido implementar un sistema de gestión de calidad, su desarrollo se encuentra en estado inicial, por lo que todavía no se evidencia su efectividad. En este sentido, se requiere implementar el uso sistemático de indicadores de gestión con el fin de orientar y monitorear el avance del plan estratégico. Del mismo modo, la institución deberá determinar e instalar las acciones necesarias que le permitan asegurar la integración de todos los sistemas informativos que se encuentran disponibles garantizando de dicho modo, la confiabilidad de la información utilizada y difundida”.

Área GI. Proceso de enseñanza-aprendizaje:

U_ULA_2013: "Para implementar dicho modelo (Modelo educativo), la institución ha establecido tres etapas: de socialización, instalación y de evaluación y ajustes. De acuerdo a [sic] lo informado por los pares evaluadores, dicho modelo se aplica a las carreras con licenciatura, pero no da respuestas específicas a la formación de carreras técnicas ni profesionales sin licenciatura".

Área GI. Recursos Materiales:

CFT_EGR_2014: "El comité de pares constató que las instalaciones, si bien permiten realizar las actividades básicas de docencia, son más bien heterogéneas y presentan insuficiencias para algunas ca- 
participación de distintas competencias. Por otro lado, se observa una débil definición, cuantificación y seguimiento del plan estratégico y de los planes de desarrollo, así como se detectan falencias en la planificación anual de los recursos y los sistemas de información en las áreas de docencia, administración y finanzas".

\section{Área DP. Docentes:}

CFT_EGR_2014: “La dotación de docentes actual es adecuada en número, apropiada en dedicación y capacidades. A pesar de estar vinculada directamente en el mundo productivo, se evidencia compromiso y conocimiento de los propósitos de la institución. No se constató la formalización de una política de recursos humanos, sino solo la existencia de mecanismos para el reclutamiento, selección y capacitación del personal docente".

Área VcM. Coherencia:

U_UMAG_2015: "La universidad cuenta con un foco institucionalizado de vinculación con el medio, alineado con la identidad y pertinencia regional, que se ha traducido en propósitos y fines claros, que orientan de modo visible el desarrollo de este ámbito". rreras (...) También son insuficientes los servicios de apoyo a los estudiantes, tales como laboratorios de computación, computadores disponibles, impresora fotocopiadora, conexión a internet inalámbrica y servicios de cafetería"

Área DP. Área de diseño y provisión de carreras:

CFT_CPA_2012: “(...) se observa heterogeneidad en la aplicación de recursos entre las sedes, la oferta académica de las sedes de la $\mathrm{n}$ región se han mantenido estática a pesar de la creación de nuevas carreras y una innovación en la provisión de carreras que responde a los requerimientos del medio en las sedes de $\mathrm{n}$ y de $\mathrm{n}$. A juicio de la comisión, la institución debe alcanzar una impronta en su proyecto educativo que responda"

Área VcM. Coherencia:

U_UMAG_2015: "Pese a que se observa que la comunidad universitaria participa del diseño y evaluación de actividades de vinculación con el medo, no se evidencia vinculación formal de los resultados obtenidos en este ámbito con la docencia de pregrado, posgrado, ni con la investigación".

Fuente: elaboración propia.

Descripción de resultados por áreas de autoevaluación, fortalezas y debilidades presentes en el grupo instituciones posterior a la adjudicación de PMI 2015 [T2]

Lo que sucede con estas instituciones en sus próximos procesos de autoevaluación, una vez que se adjudicaron un PMI 2015, tiene que ver con un giro de la CNA y su cambio en la lógica al evaluar los propósitos institucionales a partir del año 2018, según lo dispuesto por la Ley 20.129. Esto trae consigo, en un primer momento, cierta rigurosidad sobre los criterios, aspectos que deben tener cierta coordinación o correlación entre los criterios de base y que, desde la Gestión Institucional y la Vinculación con el Medio, producirán impactos significativos en el criterio general de docencia de pregrado; tales cambios se evidencian gradualmente.

Se destaca en este punto la equidad entre lo declarado en los dictámenes de acreditación, la identificación de aspectos consolidados como prácticas institucionales $\mathrm{y}$, de forma progresiva, un incremento de compromisos de mejora institucional. En estos dictámenes, lo anterior representa cierta continuidad de obstaculizadores y 
debilidades sobre cómo se ha presentado la mejora continua cuando estas instituciones se hacen acreedoras de PMI. Por tanto, la mayor parte de los dictámenes refuerza los resultados obtenidos en acreditaciones anteriores, dentro de los cuales se encuentran aspectos susceptibles de mejoramiento financiados por PMI 2015, tales como aspectos fundamentales para asegurar calidad que no han sido consolidados. Principalmente, y de forma transversal, se destaca que la mayoría de las instituciones ha debido recurrir a recursos de reposición en CNA, además de apelaciones a CNED en segunda instancia, para revertir decisiones negativas de acreditación.

En el caso de la VcM, esta no se consolidan de forma sistemática (cuadro 14) por cuanto este criterio optativo, al ser también de tipo residual y de impacto sobre los demás, aún no es valorizado con el potencial que asume la CNA en su rol protagónico para la FTNS, donde la pertinencia de la oferta académica en articulación con el entorno y medio socioproductivo, (formación dual, reconocimiento de aprendizajes previos, entre otros) debe dibujarse de tal modo que se incluya a expertos involucrados en el mundo productivo y profesional. Por lo tanto, VcM posee una baja frecuencia de enunciado (solo entre 4 y 8 menciones en calidad de fortaleza) para las instituciones que han logrado promover mejoras en ese ámbito.

Las buenas prácticas en las áreas de acreditación GI y DP tienden a visibilizarse: se acentúan la coherencia, la claridad, la socialización y el seguimiento a la misión y propósitos institucionales como un criterio clave para la organización de la institución y el despliegue de su modelo educativo a nivel general. En las instituciones analizadas sobresalen entre 20 y 27 menciones concernientes a las fortalezas en GI, y entre 11 y 19 en DP. En la de VcM subsisten brechas para concretar la promoción de sistemas que vinculen de manera efectiva la estructura organizacional, el modelo formativo y la inserción laboral con el medio socioproductivo.

La cifra de debilidades en el cuadro 14 sugiere que las instituciones, en su conjunto, enfrentaron una serie de hitos para para alcanzar los objetivos de los planes seleccionados con vistas a la mejora institucional; en tal escenario son capaces de generar una mayor cantidad de evidencias frente al PMI 2015 respecto de criterios que no fueron considerados, implementados o proyectados antes del proyecto institucional.

En virtud de lo expuesto, en los dictámenes aumentan el número de observaciones que marcan debilidades y brechas a enfrentar, lo que conlleva una reducción de años de acreditación incluso al cierre de la institución IAR, perteneciente al segmento de instituto profesional (IP) beneficiado con PMI. Los CFT, por su parte, cayeron en años hasta el punto de ser considerados instituciones ubicadas en nivel básico de acreditación. La gestión de los proyectos institucionales, referida a la materialización de las mejoras declaradas, no impacta mayormente el proceso formativo o la consolidación de los modelos educativos. 
Una de las principales debilidades detectadas en los CFT se atribuye al área DPy a dificultades en torno a criterios de homogeneización de los modelos educativos en instituciones que poseen más de una sede, además de lo que recae en el análisis de progresión y la capacidad de autorregulación de las instituciones de plantear sistemas capaces de advertir indicadores notables y logros del perfil de egreso. Con todo, aún no logran generar dinámicas desde el área de GI que viabilicen la instauración de mejoras organizacionales, modelos y diseños con un enfoque de competencias a través de las cuales observen constantemente el nivel de logro, respaldados preferentemente por inversiones en equipamiento, actualización y rediseño curricular, capacitación docente, vinculación con el medio, entre otros. Los dictámenes, sobre todo, insisten en que las debilidades son causa de una gobernanza reactiva, poco planificada y de instrumentos de promoción de buenas prácticas para el aseguramiento de la calidad que todavía se hallan en etapas de diseño e implementación.

En lo que atañe a las universidades, las comisiones de pares evaluadores reiteran una fuerte crítica a la distancia entre los modelos formativos de las carreras profesionales y las técnicas, además de las otras áreas de funcionamiento de distinto nivel formativo desde las cuales plantean su desarrollo institucional.

\begin{tabular}{|c|c|c|c|c|c|c|}
\hline \multirow{2}{*}{$\begin{array}{l}\text { Dimensiones de análisis } \\
\text { Áreas de autoevaluación }\end{array}$} & \multicolumn{3}{|c|}{ Fortalezas } & \multicolumn{3}{|c|}{ Debilidades } \\
\hline & $\begin{array}{l}\text { PROM } \\
\text { CFT }\end{array}$ & $\begin{array}{l}\text { PROM } \\
\text { IP }\end{array}$ & $\begin{array}{l}\text { PROM } \\
\text { UES }\end{array}$ & $\begin{array}{l}\text { PROM } \\
\text { CFT }\end{array}$ & $\begin{array}{l}\text { PROM } \\
\text { IP }\end{array}$ & $\begin{array}{c}\text { PROM } \\
\text { UES }\end{array}$ \\
\hline Gestión institucional & 20 & 20 & 27 & 15 & 19 & 17 \\
\hline 1.A Misión y propósitos & 4 & 4 & 4 & 1 & 1 & 2 \\
\hline 2.A Estructura organizacional & 2 & 3 & 2 & 1 & 1 & 2 \\
\hline $\begin{array}{l}\text { 3.A Capacidad de } \\
\text { autorregulación }\end{array}$ & 2 & 1 & 5 & 3 & 3 & 4 \\
\hline 4.A Gobierno institucional & 2 & 2 & 3 & 2 & 2 & 1 \\
\hline 5.A Gestión de personas & 2 & 2 & 2 & - & 1 & 1 \\
\hline 6.A Información institucional & 2 & 5 & - & 2 & 1 & 1 \\
\hline 7.A Recursos materiales & 1 & 1 & 3 & 3 & 4 & 3 \\
\hline $\begin{array}{l}\text { 8.A Sustentabilidad } \\
\text { económico-financiera }\end{array}$ & 1 & 1 & 3 & 2 & 6 & 3 \\
\hline
\end{tabular}




\begin{tabular}{|c|c|c|c|c|c|c|}
\hline 9.A Servicios de apoyo & 4 & 4 & 4 & - & - & - \\
\hline 10.A Difusión y publicidad & 1 & 1 & - & - & 1 & 1 \\
\hline Docencia Pregrado & 19 & 15 & $\mathbf{1 1}$ & 10 & 11 & 11 \\
\hline $\begin{array}{l}\text { 1.B Diseño y provisión de } \\
\text { Carreras }\end{array}$ & 3 & 3 & 3 & 2 & 3 & 3 \\
\hline $\begin{array}{l}\text { 2.B Proceso de enseñanza- } \\
\text { aprendizaje }\end{array}$ & 5 & - & 4 & 2 & - & 2 \\
\hline 3.B Innovación de contenidos & 1 & 2 & - & - & 1 & - \\
\hline 4.B Dotación & 2 & 3 & 2 & 1 & 1 & 1 \\
\hline 5.B Calificación & 3 & 3 & 2 & 1 & 2 & 1 \\
\hline 6.B Progresión & 2 & 2 & 1 & 2 & 4 & 3 \\
\hline 7.B Inserción laboral & 2 & 1 & - & - & - & - \\
\hline 8.B Seguimiento de egresados & 1 & 2 & - & 1 & 1 & 1 \\
\hline Vinculación con el medio & 4 & $\mathbf{1}$ & 8 & $\mathbf{1}$ & 2 & $\mathbf{1}$ \\
\hline 1.C Coherencia & 2 & 1 & 3 & 1 & 1 & 1 \\
\hline 2.C Condiciones de operación & - & - & 1 & - & 1 & - \\
\hline 3.C Resultados & - & - & 1 & - & 1 & - \\
\hline 4.C Impacto & 2 & - & 3 & - & - & - \\
\hline
\end{tabular}

En el cuadro 15 se aprecian las fortalezas y debilidades, de acuerdo con las evidencias de los respectivos pares evaluadores.

CUADRO 15 Fortalezas y debilidades de las instituciones analizadas

\section{Fortalezas}

Área GI, criterio de misión y Propósitos

CIC 2016: "El centro cuenta con una misión y visión conocidas y difundidas en la comunidad institucional, que dan cuenta de su carácter y valores (...) el plan de desarrollo de la institución (PED 2011-2016) contiene 6 objetivos estratégicos que han sido abordados en el periodo que se dan cuenta de los énfasis del proyecto".

Área GI, criterio de misión y propósitos:

\section{Debilidades}

Área GI, criterio de misión y propósitos:

CPA_2018: "Los cambios en el proyecto institucional ocurridos a raíz de la salida de la Cámara Chilena de la Construcción en 2017 (de la participación económica y orgánica de la institución como controladora), derivan en una reformulación acelerada en los procesos de gestión del centro, que se encuentra en etapa de transición. Esto dificulta la tarea de la comisión en la evaluación de un proyecto que ve alterada su continuidad y propósitos, 
CIC_2019: "El plan de desarrollo estratégico 2011 -2016 fue evaluado por la institución con un logro parcial de los objetivos comprometidos. EL plan actual 2017 - 2021, identifica prioridades y metas institucionales sobre la base de indicadores cuantitativos y cualitativos".

Área GI, información institucional:

CIC_2019: "El centro cuenta, desde el 2014, con el sistema Iprosoft que le permite disponer de información actualizada". con escasa posibilidad de expresar resultados en tan corto plazo".

Área GI, información institucional:

CIC 2019: "Hubo inconsistencias en la información de unos y otros documentos oficiales del centro, a modo de ejemplo, el plan de inversiones en obras, remodelaciones y habilitación de infraestructura 2017-2021, presenta diferencias entre aquel entregado como anexo previo a la visita, $y$, el documento entregado durante la visita; inconsistencia entre los estados financieros de la institución, además de la existencia de distintas versiones de la política de retiro de excedentes".

Área GI, recursos materiales:

CPA_2018: "En general, la institución cuenta con una infraestructura, instalaciones y equipamiento para el desarrollo de actividades formativas. Se identifican, ciertas diferencias en cuanto a la disponibilidad de equipos en algunas carreras que se imparten en sedes. Por ejemplo, el equipamiento de simulación de soldaduras de ato estándar solo existe en una sede y no en otras".

Área DP, recursos materiales:

ULA 2016: "No existen estándares mínimos de equipamiento e infraestructura dispuestos desde la Universidad, sino que se levantan necesidades desde los docentes y jefes de carreras y, conforme a la disponibilidad presupuestaria, se atiende a las demandas (...) no se percibe que la planificación contemple una relación fluida entre los requerimientos de los usuarios y las correspondientes respuestas, y depende para su materialización de la captación de proyectos concursales. Tampoco cuenta con un plan de largo plazo para el equipo tecnológico".

Área DP: Diseño y provisión de carreras.

ULA_2016: "El modelo educativo está en etapa de implementación y su instalación no es homogénea en todas las carreras y sedes. A partir del año 2010 se concentró en carreras profesionales con licenciatura, mientras que en las carreras profesionales sin licenciatura y carreras técnicas está sin implementarse". 


\section{Conclusiones}

Con lo visto, el trabajo descrito alcanzó su propósito principal: analizar la incidencia de los PMI en el aseguramiento de la calidad de las instituciones que imparten FTNS en Chile, antes y después de que fuese ratificada la acreditación institucional, y luego de implementarse estos planes. Para esto fue necesario sumergirse en los acuerdos de acreditación de siete instituciones que se adjudicaron financiamiento.

Sumado a lo anterior, se ha establecido una relación con los años de acreditación obtenidos, con lo cual se revelaron fortalezas y debilidades por áreas y criterios de acreditación; es decir, se consiguió identificar dónde se ha avanzado en materia de aseguramiento de la calidad y cuáles son los nudos críticos que aún afectan el mejoramiento de los procesos en la FTNS.

Reconocer estos aspectos resulta relevante y orientador para el sistema educativo chileno, sobre todo cuando se busca poner en práctica una "Estrategia Nacional de Formación Técnico Profesional" encaminada a fortalecer el área respecto de la articulación del sistema, en sus diversos niveles, con los requerimientos formativos locales y nacionales, y con trayectorias laborales adecuadas a necesidades personales y de sectores productivos que, a la postre, aporten a resultados adecuados de titulación y a una mayor inserción laboral, como lo indica la Ley 20.091 de Educación Superior.

Uno de los principales hallazgos del estudio alude al número de años de acreditación alcanzados en correspondencia con la adjudicación de un PMI. Se comprobó que no existe una relación directa entre la adjudicación y la puesta en marcha de un PMI con asignación de recursos estatales, sino más bien una distancia considerable en la mayoría de los planteles luego de ejecutados los PMI ya que se advierten fuertes debilidades institucionales en el marco de las acreditaciones, que persisten e inciden de forma significativa en el posicionamiento de la institución. Esto corrobora lo señalado por Cancino y Small (2014: 49) acerca de que resulta un indicador de éxito del proceso de acreditación la cantidad de años de obtenidos, y ello incidirá en la valoración que se haga de la institución en el contexto externo.

Una vez adjudicados los PMI 2015, las instituciones comenzaron a realizar cambios sustanciales en sus propósitos institucionales, esquemas organizacionales y modelos educativos, entre otras áreas; de ello surgieron avances desde la implementación del modelo basado en competencias, lo que fue impulsado principalmente por estos mecanismos de fortalecimiento. Así, las instituciones comenzaron un proceso de reformulación importante en sus modelos formativos, pero a la fecha no se poseen evidencias consistentes o formas de sistematización que den cuenta de impactos considerables en los perfiles de egreso, y en general, en la calidad de la FTNS que imparten (Muga; Sotomayor; Baeza, 2017). Se evidencia desde los 
dictámenes de acreditación que, una vez implementadas estas mejoras, la mayoría de las instituciones presentaron dificultades para proveer sistemas de información empleados por las instituciones ya acreditadas y beneficiadas, sin instalar mecanismos para el seguimiento y la progresión de los estudiantes, tampoco capitalizar a los titulados y la inserción laboral, uno de los desafíos de articulación con el medio socioproductivo más relevantes en este nivel formativo.

Si bien es cierto que la mayoría de las instituciones tenían una declaración de la relevancia de los mecanismos VcM en su relación con los perfiles de egreso, en la etapa posterior a los PMI la exigencia implicaba consolidarlos plenamente en la definición y evaluación de estos perfiles, cuestión que las instituciones tienen parcialmente o escasamente resuelta frente a los desafíos de actualización y cercanía con los sectores socioproductivos, de los cuales proviene la demanda formativa. Asimismo, se identificó una de las fortalezas del PMI, que según lo planteado por Reich et al. (2011: 14) apunta al seguimiento y monitoreo continuo sobre la base de control permanente: es notorio que dicho seguimiento se instale de manera continua en la institución y comprometa a actores como la propia CNA, en una tutoría de monitoreo que garantice una articulación efectiva entre financiamiento público invertido y movilización de indicadores claves.

Pese a lo anterior, no parece razonable ni eficiente el diseño e implementación de un instrumento de asignación de recursos públicos que conlleve el cierre de una institución elegida como destinataria de este presupuesto. A respecto, se ha visibilizado que fallaron los mecanismos de seguimiento hacia la institución y, quizá también, su elegibilidad por parte de los tomadores de decisiones académicas y presupuestales. Esta situación puede asociarse con el concepto de ineficiencia técnica asociada al malgasto en el gasto público (Banco Interamericano de Desarrollo - BID, 2018: 52), situación preocupante en países donde este gasto en instituciones por estudiantes es uno de los más bajos entre los miembros de la Organización para la Cooperación y el Desarrollo Económicos (OCDE) y el financiamiento privado es particularmente significativo en educación superior (OCDE, 2019). Por ello, y dado que la lógica del financiamiento público de la educación superior en Chile se configura principalmente a través de asignación de fondos concursables por sobre aportes directos, urge repensar en el perfeccionamiento del instrumento de asignación de estos limitados recursos.

Por otra parte, parece lógico afirmar que los Centros de Formación Técnica (CFT) deberían estar mejor preparados que los Institutos Profesionales (IP) y las universidades para ocuparse específicamente de la FTNS en Chile. Además, las distancias creadas entre sus modelos organizacionales se han debilitado producto de la amplia complejidad, de la demanda del segmento de la inserción del medio socio 
productivo como actor relevante y promotor de requerimientos de especialización, y de la actualización de competencias, entre otras causas.

Bernasconi (2006) constató hace décadas que

no se evidencia el uso sistemático de la información del medio externo para diseñar o actualizar carreras, no se hace seguimiento de egresados para retroalimentar la enseñanza, y los profesores no son entrenados en las particularidades de la educación de técnicos o de adultos trabajadores. (4)

Estas cuestiones siguen siendo hoy un tremendo desafío para las instituciones que imparten la FTNS, aun cuando por años se ha tratado de seguir la trayectoria de países donde se garantiza el aseguramiento de la calidad, dadas sus buenas experiencias de articulación con el medio socioproductivo como eje clave en el momento de pensar y desarrollar la oferta educativa.

Pese a que se confirma que las instituciones, una vez que se adjudicaron los PMI 2015, iniciaron un amplio desarrollo y asumieron nuevos desafíos sobre calidad y mejoramiento de los servicios educacionales, la realidad muestra una tangible debilidad en cuanto a su implementación y, por lo tanto, una brecha entre los propósitos del PMI como herramienta de mejora institucional y de las condiciones institucionales para llevar adelante dichas mejoras.

Sería muy provechoso reflexionar acerca de los beneficios que trae la realización de tutorías de acompañamiento desde otras casas de estudio con proyectos de desarrollo en etapas de consolidación para instituciones que se adjudican financiamiento a través de recursos del Estado. Desde la perspectiva comparada, lo anterior se encaminaría a lograr sustentar la inversión de recursos públicos mediante la búsqueda e implementación de mejoras considerables y perfeccionar el modelo de asignación del recurso, seguimiento y monitoreo por parte de las entidades públicas financiadoras. Así mismo, es importante que los planes de mejoramiento logren anclarse en el nivel estratégico institucional y focalizarse en instituciones con condiciones de asumir tales desafíos.

Como ha quedado de manifiesto, es evidente que este sector educativo representa una enorme oportunidad para seguir investigando; tales caminos permitirán generar nuevo conocimiento, respecto de un sector tan relevante para el crecimiento y progreso de los países. 


\section{Referencias}

Banco Interamericano de Desarrollo - BID (2018). Mejor Gasto para Mejorar Vidas. Cómo América Latina y el Caribe puede hacer más con menos. Recuperado de https://publications. iadb.org/publications/spanish/document/Mejor-gasto-para-mejores-vidas-C\% $3 \%$ B3moAm\%C3\%Agrica-Latina-y-el-Caribe-puede-hacer-m\%C3\%A1s-con-menos.pdf

Bauer, Waldemar; Gessler, Michael (2016). Dual Vocational Education and Training Systems in Europe: Lessons learned from Austria, Germany and Switzerland. En Vocational Education and Training in Sub-Saharan Africa: Current Situation and Development (pp. 4866), editado por Friedhelm Eicker; Gesine Haseloff; Bernd Lennartz. Bielefeld (Germany): W. Bertelsmann Verlag. http://dx.doi.org/10.3278/6004570w

Bernasconi, Andrés (2009). Donde no somos tigres: problemas de la formación técnica en Chile en el contexto latinoamericano. Foco, 72, 14-16. Recuperado de https://www.inacap. cl/tportal/portales/tp4964boe1bk102/uploadImg/File/EducacionSuperior/4_Problemas_ Formacion_Tecnica_Chile.pdf

Biblioteca Nacional de Chile (2016). De la Escuela de Artes y Oficios a la Universidad de Santiago. La Educación Técnica en Chile. Recuperado de http://www.memoriachilena.gob. $\mathrm{cl} / 602 / \mathrm{w3}$-article-682.html

Cancino, Víctor; Schmal, Rodolfo (2014). Sistema de Acreditación Universitaria en Chile: ¿cuánto hemos avanzado? Estudios Pedagógicos, 4O(1), 41-6o. http://dx.doi.org/10.4067/ So718-07052014000100003

Comisión Nacional de Acreditación - CNA (2013). Pautas de Evaluación de Acreditación Institucional. Centros de Formación Técnica. Comisión Nacional de Acreditación. Recuperado dehttps://www.cnachile.cl/Documentos\%2ode\%2oPaginas/PAUTAS_EVAL_AI_CFT.pdf

Comisión Nacional de Acreditación - CNA (2014). Reglamento que fija el Procedimiento para el Desarrollo de los Procesos de Acreditación Institucional. Resolución exenta DJ n. oo9-4. Comisión Nacional de Acreditación. Recuperado de https://www.cnachile.cl/ Documentos\%20de\%2oPaginas/Reglamento_AI_24102014.pdf

Comisión Nacional de Acreditación-CNA (2019). Reglamento que fija el procedimiento para el desarrollo de los procesos de acreditación institucional. Diario oficial de Chile. Recuperado de https://www.cnachile.cl/SiteAssets/Paginas/Acreditacion-institucional/DO_AI.pdf

Comisión Nacional de Acreditación (2021). Buscador avanzado de acreditaciones. Recuperado de https://www.cnachile.cl/Paginas/buscador-avanzado.aspx

Comisión Nacional de Productividad (2018). Informe de Formación de Competencias Laborales. Santiago de Chile: Comisión Nacional de Productividad. Recuperado de https://www. comisiondeproductividad.cl/wp-content/uploads/2018/o3/Informe_Formacion-de_ Competencias-para_el_Trabajo.pdf 
Consejo Nacional de Educación - CNED (2017). Índices tendencias educación superior 2017. Recuperado de https://www.cned.cl/sites/default/files/tendencias_matricula_ pregrado_2017.pdf

Consejo Nacional de Educación - CNED (2020). Matrícula total educación superior 2005-2020. Consejo Nacional de Educación. Recuperado de https://www.cned.cl/indices/matriculasistema-de-educacion-superior

Donoso, Sebastián; Corvalán, Óscar (2012). Formación técnica y aseguramiento de la calidad: enfoque de desarrollo de competencias. Cadernos de Pesquisa, 42(146), 612-639. http:// dx.doi.org/10.1590/So100-15742012000200015

El Mercurio On-Line - EMOL (2017). "Déficit de profesionales técnicos en Chile: ¿En qué sectores se necesitan más?”. Recuperado de https://goo.gl/uCeyNq

Flick, Uwe (2015). El diseño de Investigación Cualitativa. Madrid: Ediciones Morata.

Geoffroy, Esteban (2014). Origen y características del sistema de aseguramiento de la calidad de la educación superior chileno. Revista Electrónica Interuniversitaria de Formación del Profesorado, 17(3), 49-64. http://dx.doi.org/10.6018/reifop.17.3.204051

Hinrichsen, Carlos (2003). Proyecto Fondef: educación del diseño basada en competencias: un aporte a la competitividad. Recuperado de https://goo.gl/Vnn3 $\mathrm{Nr}$

Lašáková, Anna; Bajzíková, L'ubica; Dedze, Indra (2017). Barriers and drivers of innovation in higher education: Case study-based evidence across ten European universities. International Journal of Educational Development, 55, 69-79. https://doi.org/10.1016/j. ijedudev.2017.06.002

Lemaitre, María José; Maturana, Mario;Zenteno, Elisa; Alvarado, Andrea (2012). Cambios en la gestión institucional en universidades, a partir de la implementación del sistema nacional de aseguramiento de la calidad: la experiencia chilena. Calidad en la educación, 36, 21-52. https://dx.doi.org/10.4067/So718-45652012000100001

Ley 20.219 de 2006 (23 de octubre), por la cual se establece un Sistema de Aseguramiento de la Calidad de la Educación Superior. Biblioteca Nacional del Congreso, Santiago de Chile. Recuperado de https://www.leychile.cl/Navegar?idNorma=255323

Ley 21.091 de 2018 (11 de mayo), por la cual se crea un sistema de educación superior. Biblioteca Nacional del Congreso, Santiago de Chile. Recuperado de https://www.leychile. $\mathrm{cl} /$ Navegar?idNorma $=1118991$

Mininsterio de Educación - Mineduc - (2015). Resolución Excenta 5042 de 06 julio de 2015. Recuperado de http://dfi.Mineduc.cl/usuarios/MECESUP/File/2015/convocatorias/ PMI_FTP/PRESPMIFTPREX50422015.pdf 
Ministerio de Educación - Mineduc (2017). Informe de titulación en educación superior en Chile 2017. Recuperado de https://www.mifuturo.cl/wp-content/uploads/2018/SIES/ informes_anuales/titulados/informe\%2otitulacion\%202017_sies.pdf

Ministerio de Educación - Mineduc (2018). Estrategia Nacional de Formación Técnico Profesional. Ministerio de Educación. Recuperado de http://www.tvetchile.org/wpcontent/uploads/2018/o3/Estrategia-Nacional-de-Formaci\%C3\%B3n-T\%C3\%A9cnicoProfesional-febrero-2018.pdf

Ministerio de Educación - Mineduc (2021a). Sistema de Información de Educación Superior (SIES). Centros de Formación Técnica. Recuperado de https://www.mifuturo.cl/centrosde-formacion-tecnica-cft/

Ministerio de Educación - Mineduc (2021b). Sistema de Información de Educación Superior (SIES). Base de datos de matrículas en instituciones educación superior. Ministerio de Educación. Recuperado de https://www.mifuturo.cl/bases-de-datos-de-matriculados

Ministerio de Educación y Ministerio del Trabajo y Previsión Social (2020). Estrategia Nacional de Formación Técnico Profesional. Ministerio de Educación. Recuperado de https:// educacionsuperior.Mineduc.cl/wp-content/uploads/sites/49/2020/12/Estrategia-FTP.pdf

Miranda, Martín (2003). Transformación de la Educación Media Técnico Profesional. En Políticas educacionales en el cambio de siglo (pp.375-417), editado por Cristián Cox. Santiago de Chile: Editorial Universitaria.

Muga, Alfonso; Sotomayor, Alejandro; Baeza, Pablo (2017). Logros e impactos de los perfiles de egreso: evidencias y desafíos. En Evaluación del logro de perfiles de egreso: experiencias universitarias (177-188), editado por el Centro Interuniversitario de Desarrollo - Cinda. Santiago de Chile: Cinda.

Organización para la Cooperación y el Desarrollo Económicos - OCDE (2019). Panorama de la Educación en Chile. Indicadores de la OCDE. Recuperado de https://slideplayer.es/ slide/17610160/

Pineda-Herrero, Pilar; Ciraso-Calí, Anna; Arnau-Sabates, Laura (2019). La FP dual desde la perspectiva del profesorado: elementos que condicionan su implementación en los centros. Educación XX1, 22(1), 15-43. http://dx.doi.org/10.5944/educXX1.21242

Programa Mejoramiento de la Calidad y Equidad de la Educación Superior - Mecesup (2014). Manual Operacional del Programa de Financiamiento por Resultados de la Educación Terciaria -3. Ministerio de Educación. Recuperado de http://dfi.Mineduc.cl/usuarios/ MECESUP/File/2015/operaciones/CLMECE3MOPERAT20102014.pdf

Programa Mejoramiento de la Calidad y Equidad de la Educación Superior - Mecesup (2015). Resolución Exenta n. ${ }^{\circ} 2$ de 2015. Ministerio de Educación. Recuperado de http://dfi. Mineduc.cl/usuarios/MECESUP/File/2015/convocatorias/PMI_FTP/Adj-327-FTP.pdf 
Reich, Ricardo; Machuca, Flora; López, Daniel; Prieto, Juan; Music, Juan; Rodríguez-Ponce, Emilio; Yutronic, Jorge (2011). Bases y desafíos de la aplicación de convenios de desempeño en la educación superior de Chile. Ingeniare. Revista chilena de ingeniería, 19(1), 8-18. http:// dx.doi.org/10.4067/So718-33052011000100002

Romero, Rosa; Montt, Blanca; Arancibia, María (2020). Caracterización de las condiciones institucionales que favorecen u obstaculizan el desarrollo de la innovación educativa en la Educación Superior Técnico Profesional. Santiago de Chile: Comisión Nacional de Acreditación. Recuperado de https://www.cnachile.cl/SiteAssets/Paginas/cuadernos/ Cuaderno\%2019.pdf

Sevilla, María (2014). La educación técnica en Chile y Estados Unidos desde una perspectiva histórica y comparada. Calidad en la educación, 40, 297-317. https://dx.doi.org/10.4067/ So718-45652014000100010

Sevilla, María (2017). Panorama de la educación técnica profesional en América Latina y el Caribe. Santiago de Chile: Cepal.

Sistema de información de Tendencias Educativas en América Latina-Siteal (2019).Educación y Formación Técnica Profesional. Santiago de Chile: Unesco-IIEP. Recuperado de https:// www.siteal.iiep.unesco.org/eje/educacion_y_formacion_tecnica_y_profesional

Unesco (1999). Recomendaciones Segundo Congreso Internacional sobre Enseñanza Técnica y Profesional - Seúl.

Unesco (2003). Enseñanza y formación técnica y profesional en el siglo XXI: recomendaciones de la Unesco.Unesco. Recuperado de https://unesdoc.unesco.org/ark:/48223/pfoooo126050_spa

Unesco (2012). Recomendaciones del Tercer Congreso Internacional sobre Educación y Formación Técnica y Profesional "Transformar la EFTP: forjar competencias para el trabajo y la vida”. Unesco. Recuperado de https://unevoc.unesco.org/fileadmin/up/shanghaispanish.pdf

Unesco (2015a). Qué es la EFTP. Unesco. Recuperado de https://unevoc.unesco.org/home/ Que+es+la+EFTP

Unesco (2015b). Recomendación relativa a la enseñanza y formación técnica y profesional (EFTP). Unesco. Recuperado de http://portal.unesco.org/es/ev.php-URL_ID=49355\&URL_ DO=DO_TOPIC\&URL_SECTION=201.html

Unesco (2016). Estrategia para la enseñanza y formación técnica y profesional (EFTP) (2016-2021). Paris: Unesco. Recuperado de https://unevoc.unesco.org/ go.php?q=Estrategia+para+la+EFTP+2O16-2021

Wiendenslaufer, Pamela; Cifuentes, Mauricio; Guerrero, Holz (2015). Educación técnica profesional: los casos de Alemania, Australia y Canadá. Biblioteca del Congreso Nacional de Chile. Recuperado de https://www.bcn.cl/asesoriatecnicaparlamentaria/detalle_documento. html?id=26694 